\title{
Contrasting effects of sunitinib within in vivo models of metastasis
}

\author{
Jonathan C. Welti - Thomas Powles $\cdot$ Shane Foo $\cdot$ Morgane Gourlaouen • \\ Natasha Preece · Julie Foster · Sophia Frentzas • Demelza Bird · Kevin Sharpe • \\ Antoinette van Weverwijk · David Robertson · Julie Soffe · Janine T. Erler • \\ Roberto Pili • Caroline J. Springer · Stephen J. Mather · Andrew R. Reynolds
}

Received: 24 February 2012/ Accepted: 16 July 2012/ Published online: 28 July 2012

(C) The Author(s) 2012. This article is published with open access at Springerlink.com

\begin{abstract}
Sunitinib is a potent and clinically approved tyrosine kinase inhibitor that can suppress tumour growth by inhibiting angiogenesis. However, conflicting data exist regarding the effects of this drug on the growth of metastases in preclinical models. Here we use 4T1 and RENCA tumour cells, which both form lung metastases in Balb/c mice, to re-address the effects of sunitinib on the progression of metastatic disease in mice. We show that treatment of mice with sunitinib prior to intravenous
\end{abstract}

J. C. Welti $\cdot$ S. Foo · M. Gourlaouen $\cdot$ S. Frentzas $\cdot$ J. Soffe ·

A. R. Reynolds $(\square)$

Tumour Biology Team, Breakthrough Breast Cancer Research

Centre, The Institute of Cancer Research, Fulham Road,

London SW3 6JB, UK

e-mail: andrew.reynolds@icr.ac.uk

T. Powles $\cdot$ J. Foster $\cdot$ K. Sharpe $\cdot$ S. J. Mather Centre for Molecular Oncology, Barts Cancer Institute-A CRUK Centre of Excellence, Queen Mary University of London, John Vane Science Centre, Charterhouse Square,

London EC1M 6BQ, UK

\section{N. Preece $\cdot$ C. J. Springer}

Gene and Oncogene Targeting Team, The Institute of Cancer Research, Cancer Research UK Centre for Cancer Therapeutics, 15 Cotswold Road, Sutton, Surrey SM2 5NG, UK

\section{Bird · J. T. Erler}

Tumour Hypoxia and Metastasis Team, The Institute of Cancer Research, Fulham Road, London SW3 6JB, UK

A. van Weverwijk $\cdot$ D. Robertson

Molecular Cell Biology Team, Breakthrough Breast Cancer

Research Centre, The Institute of Cancer Research,

Fulham Road, London SW3 6JB, UK

R. Pili

Roswell Park Cancer Institute, Elm \& Carlton Streets, Buffalo, NY 14263-0001, USA injection of tumour cells can promote the seeding and growth of 4T1 lung metastases, but not RENCA lung metastases, showing that this effect is cell line dependent. However, increased metastasis occurred only upon administration of a very high sunitinib dose, but not when lower, clinically relevant doses were used. Mechanistically, high dose sunitinib led to a pericyte depletion effect in the lung vasculature that correlated with increased seeding of metastasis. By administering sunitinib to mice after intravenous injection of tumour cells, we demonstrate that while sunitinib does not inhibit the growth of 4T1 lung tumour nodules, it does block the growth of RENCA lung tumour nodules. This contrasting response was correlated with increased myeloid cell recruitment and persistent vascularisation in 4T1 tumours, whereas RENCA tumours recruited less myeloid cells and were more profoundly devascularised upon sunitinib treatment. Finally, we show that progression of $4 \mathrm{~T} 1$ tumours in sunitinib treated mice results in increased hypoxia and increased glucose metabolism in these tumours and that this is associated with a poor outcome. Taken together, these data suggest that the effects of sunitinib on tumour progression are dosedependent and tumour model-dependent. These findings have relevance for understanding how anti-angiogenic agents may influence disease progression when used in the adjuvant or metastatic setting in cancer patients.

Keywords Angiogenesis - Metastasis - Resistance · VEGF · Breast · Renal

\section{Introduction}

Sunitinib is an orally available tyrosine kinase inhibitor that potently inhibits vascular endothelial growth factor 
(VEGF) receptors (VEGFR1, VEGFR2 and VEGFR3), platelet derived growth factor (PDGF) receptors (PDGFR $\alpha$ and PDGFR $\beta$ ) and several other receptor tyrosine kinases, including KIT receptor $[1,41,46]$. Extensive preclinical work shows that inhibitors of vascular endothelial growth factor signalling, such as sunitinib, can suppress tumour growth in mice by inhibiting tumour angiogenesis [2, 20, $25,28,32,33,48,60]$. Moreover, sunitinib has been shown to extend progression free survival and overall survival in patients with metastatic renal cell carcinoma (mRCC) and is now used as first line treatment for this disease [44, 45].

Despite these promising results, $20-30 \%$ of mRCC patients show no response to sunitinib and even those that do respond initially will inevitably develop resistance and progress after several months of treatment [30, 45, 50]. This scenario is not unique, because similar findings are observed with VEGF-targeted agents in other indications. In trials of the VEGF neutralising antibody bevacizumab in metastatic breast, colorectal and lung cancer, only a subset of patients benefit from the combined use of bevacizumab with chemotherapy and the survival benefit afforded is measured only in terms of months or is not significant compared to chemotherapy alone [23, 35, 43, 51].

Importantly, preclinical studies are revealing mechanisms that allow tumours to exhibit intrinsic or acquired resistance to VEGF-targeted agents. These mechanisms include the stimulation of angiogenesis by alternative pro-angiogenic growth factors, the enhanced recruitment of pericytes or proangiogenic myeloid cells or the utilisation of alternative tumour vascularisation mechanisms such as vascular cooption [5, 7, 19, 38, 53]. In addition to these mechanisms of resistance, more recent work suggests that pharmacological inhibition of angiogenesis could also accelerate the growth of metastases. Treatment of several tumour models with VEGF receptor inhibitors, prior to resection of the primary tumour, lead to the increased incidence of distant metastasis in mice $[13,47,52]$. These data imply that the use of antiangiogenic agents in the neoadjuvant setting could potentially promote the progression of metastases in patients. Further to this, administration of sunitinib after resection of the primary tumour increased the incidence of metastasis in mice [18]. In the same study, treatment of mice with sunitinib prior to, or after, intravenous injection of tumour cells also promoted the growth of metastases [18]. These data imply that anti-angiogenic agents could accelerate the growth of metastases both in the adjuvant setting and in patients with established metastatic disease. Although the analysis of large clinical studies currently provides no evidence for accelerated growth of metastasis in patients treated with clinically approved agents such as sunitinib or bevacizumab [21, 22, $39,42]$, rapid tumour regrowth has been observed in some individuals after withdrawing anti-angiogenic therapy $[6$, $10]$.
Contradictory evidence therefore exists regarding the ability of VEGF-targeted agents to control the growth of metastasis. Here we examined the effect of sunitinib on the growth of metastases in mice when it was administered either prior to or following intravenous injection of tumour cells. We identify mouse models of metastasis that show contrasting responses to sunitinib and use these to examine the effects of this drug on tumour growth and outcome.

\section{Materials and methods}

Mice, reagents and cell lines

Female Balb/c mice were obtained from Charles River UK Ltd (Margate, Kent, UK). Sunitinib malate was obtained from LC laboratories (Woburn, MA, USA). Tissue culture reagents were obtained from Invitrogen Ltd (Paisley, Renfrewshire, UK), except for endothelial cell mitogen that was obtained from Serotech (Kidlington, Oxon., UK). Unless otherwise stated, all other reagents were obtained from Sigma (Poole, Dorset, UK). The 4T1 murine mammary carcinoma cell line that stably expresses the luciferin gene (4T1-luc) was obtained from Caliper Life Sciences (Runcorn, Cheshire, UK). The RENCA murine renal carcinoma cell line that stably expresses the luciferin gene (RENCAluc) was prepared as previously described [60]. Tumour cell lines were cultured in RPMI medium supplemented with $10 \%$ foetal calf serum (FCS) in $5 \% \mathrm{CO}_{2}$ at $37{ }^{\circ} \mathrm{C}$. Human umbilical vein endothelial cells (HUVECs) from pooled donors (TCS Cell Works, Buckingham, Bucks., UK) were cultured in HUVEC-specific medium (M199 medium supplemented with $20 \% \mathrm{FCS}, 20 \mu \mathrm{g} / \mathrm{ml}$ endothelial cell mitogen, $10 \mu \mathrm{g} / \mathrm{ml}$ heparin and antibiotics) in $8 \% \mathrm{CO}_{2}$ at $37^{\circ} \mathrm{C}$. HUVECs were used for experiments at passage 4-8.

\section{Preparation of sunitinib for oral dosing}

Vehicle for sunitinib consisted of $0.5 \%$ w/v carboxymethylcellulose sodium, $1.8 \%$ w/v NaCl, $0.4 \%$ w/v Tween- 80 , $0.9 \% \mathrm{w} / \mathrm{v}$ benzyl alcohol dissolved in reverse osmosis deionised water adjusted to $\mathrm{pH}$ 6.0. For oral dosing, sunitinib malate powder was added to vehicle and vortexed to create a suspension. This drug suspension was prepared at least $24 \mathrm{~h}$ before administration and stored at $4{ }^{\circ} \mathrm{C}$ in the dark. Fresh stocks of sunitinib suspension were prepared every week. Oral dosing in mice was performed by administration of $0.2 \mathrm{ml}$ of vehicle or sunitinib suspension by oral gavage.

In vivo tumour models and bioluminescence imaging

To examine the effect of sunitinib on the growth of lung metastases, female Balb/c mice at 8-10 weeks of age were 
injected intravenously with 4T1-luc or RENCA-luc tumour cells $\left(2 \times 10^{5}\right.$ cells in $\left.100 \mu \mathrm{l}\right)$. Where pre-treatment was employed, mice were administered vehicle or sunitinib at the indicated dose by oral gavage every day for 7 days and cells were injected $24 \mathrm{~h}$ after the last dose was administered. Where treatment was administered after intravenous tumour cell injection, mice commenced treatment $24 \mathrm{~h}$ after injection with cells. Humane endpoints were used to measure the survival of tumour bearing mice in accordance with UK Home Office guidelines. Specifically, mice were culled when they developed any of the following clinical signs: loss of $20 \%$ body mass, dypsnea, ataxia or seizure. For IVIS imaging, mice were injected intraperitoneally with $75 \mathrm{mg} / \mathrm{kg}$ D-luciferin (Caliper Life Sciences Hopkinton, MA), immediately anaesthetised with isofluorane and then imaged. Imaging was performed using a Lumina II $^{\mathrm{TM}}$ IVIS (In Vivo Imaging System) instrument (Caliper Life Sciences) with quantification of bioluminescence performed using Living Image ${ }^{\mathrm{TM}}$ software (Caliper Life Sciences) according to manufacturers instructions.

\section{Measuring plasma concentrations of sunitinib}

Female Balb/c mice at $8-10$ weeks of age were treated with either a single dose of drug, or for seven days with drug (30, 60 or $120 \mathrm{mg} / \mathrm{kg} /$ day sunitinib) by oral gavage. At the appropriate time point, blood was collected by cardiac puncture under terminal anaesthesia. Blood samples were spun at $250 \mathrm{~g}$ for $10 \mathrm{~min}$ to isolate the plasma fraction, which was then stored in $100 \mu$ l aliquots at $-20{ }^{\circ} \mathrm{C}$ until analysis. Calibration standards, ranging from $5 \mathrm{nM}$ to $100 \mu \mathrm{M}$ final sunitinib concentration, were prepared by spiking $100 \mu \mathrm{l}$ samples of control mouse plasma with sunitinib. Calibration standards and test samples were precipitated with methanol, vortexed and then centrifuged at $21,000 \mathrm{~g}$ for $30 \mathrm{~min}$ at $4{ }^{\circ} \mathrm{C}$. The supernatant was then transferred to clean autosampler vials for subsequent analysis, which was performed on a quadrupole ion trap mass spectrometer with electrospray in positive ionisation mode (Thermo Scientific, Hemel Hempstead, Herts., UK).

Tumour histology and immunohistochemistry

For ex vivo quantification of tumour burden, formalin fixed paraffin embedded sections of mouse lung were stained with haematoxylin and eosin (H\&E) and then digitally scanned using an automated scanning microscope (Ariol system, Leica Microsystems Ltd, Milton Keynes, Bucks., UK). Tumour burden in the scanned images was measured using Adobe Photoshop image analysis software (Adobe, Uxbridge, Middx., UK). In brief, the marquee tool was used freehand to create regions of interest (ROIs) around areas of tumour in the section. The area of these ROIs was then calculated by the software and added together $(\mathrm{t})$. The total area of the section ( $\mathrm{T})$ was measured using the same freehand ROI method. The percentage area of lung section that was occupied by tumour was then calculated according to this formula: $(\mathrm{t} / \mathrm{T}) \times 100$. Lesion diameters were measured using the ruler tool in Adobe Photoshop.

Immunohistochemistry was performed in frozen tissue sections. At sacrifice, lungs were embedded in OCT on dry ice immediately following resection, followed by preparation of frozen sections $(30 \mu \mathrm{M}$ sections for analysis of tumour cell seeding and pericyte coverage in lung vasculature, $8 \mu \mathrm{M}$ for all other studies). For staining, sections were brought to room temperature, fixed in $4 \% \mathrm{w} / \mathrm{v}$ formalin for 10 min followed by incubation in blocking buffer (PBS supplemented with $1 \%$ BSA and $10 \mu \mathrm{g} / \mathrm{ml}$ normal goat serum) for $1 \mathrm{~h}$ and then incubation with primary antibodies in blocking buffer overnight at $4{ }^{\circ} \mathrm{C}$. Primary antibodies used were as follows: rat anti-CD31 (BD Biosciences, Oxford, Oxon., UK), rabbit anti-NG2 proteoglycan (Millipore, Billerica, MA), FITC-conjugated mouse anti-pimonidazole (HPI Inc., Burlington, MA), Alexa-488 conjugated rat anti-Gr1, phycoerythrin-conjugated rat antiCD11b (Biolegend, San Diego, CA), biotin-conjugated rat anti-CD31 (BD Biosciences), rabbit anti-CAIX and rabbit anti-GLUT1 (Abcam, Cambridge, UK). After $3 \times 5$ min washes in PBS, sections were incubated with fluorescently conjugated secondary antibodies and/or fluorescently conjugated streptavidin and/or DAPI (Invitrogen Ltd) for $2 \mathrm{~h}$ at room temperature. After $3 \times 5$ min washes in PBS, sections were mounted with a glass coverslip in MOWIOL mounting solution supplemented with antifade $(0.1 \% \mathrm{w} / \mathrm{v}$ 1,4-diazabicyclo[2.2.2] octane).

Images were captured using a confocal laser scanning microscope (Leica) or the Ariol System automated scanning microscope (Leica). For studies of cell seeding in the lungs, cells were labeled with $10 \mu \mathrm{M}$ carboxyfluorescein diacetate succinimidyl ester (Invitrogen) as per the manufacturers instructions just prior to intravenous injection. The number of fluorescent cells seeded per lung section was determined by counting using a fluorescence microscope. To determine pericyte coverage of vessels, confocal images of CD31 and NG2 staining were captured and the percentage of CD31 pixels that colocalised with NG2 pixels was calculated using a colocalisation plug-in for ImageJ. To determine microvessel density, the number of CD31 positive vessels present within the viable tissue in each tumour nodule was counted manually. For quantification of pimonidazole staining, mice were injected intraperitoneally with $60 \mathrm{mg} / \mathrm{kg}$ pimonidazole hydrochloride in $100 \mu \mathrm{l}$ of saline at $1 \mathrm{~h}$ prior to sacrifice. To measure pimonidazole staining, Adobe Photoshop software was used to draw freehand ROIs around areas of positive staining, followed by automatic calculation of the area by 
the software. To determine the number of $\mathrm{Gr} 1+/ \mathrm{CD} 11 \mathrm{~b}+$ dual positive cells, Adobe Photoshop was used to create multi-channel images and cells labeling for both markers in each nodule were counted manually by an observer that was blinded. Areas were calculated in Adobe Photoshop using a freehand ROI method. These data were then used to calculate (a) the number of tumour cells seeded per $\mathrm{mm}^{2}$, (b) the microvessel density per $\mathrm{mm}^{2}$, (c) the $\%$ area of tumour that stained positive for pimonidazole, and (d) the number of Gr1/CD11b dual positive cells per $\mathrm{mm}^{2}$. On average, 20-40 tumour lesions were sampled from 6 to 8 mice to generate each data point.

\section{${ }^{18}$ FDG-PET/CT imaging}

Female Balb/c mice at $8-10$ weeks of age were injected intravenously with 4T1-luc or RENCA-luc tumour cells $\left(2 \times 10^{5}\right.$ cells in $\left.100 \mu \mathrm{l}\right)$. The following day, mice began treatment with vehicle or $60 \mathrm{mg} / \mathrm{kg} /$ day sunitinib on a continuous dosing schedule. Mice were imaged on the indicated days after tumour cell injection. On the day of imaging, mice were starved for at least $4 \mathrm{~h}$ prior to being anaesthetised and injected via the tail vein with $5-15 \mathrm{Mbq}$ of ${ }^{18} \mathrm{FDG}$. This was then followed by a 90 min uptake period under continuous isoflurane anaesthesia before PET images were acquired. CT and PET scanning was performed using an Inveon microPET/ CT scanner (Siemens, Munich, Germany). Isoflurane anaesthesia was continued for the duration of the scans (approximately $6 \mathrm{~min}$ for the attenuation CT and $20 \mathrm{~min}$ for the PET acquisition). Mice were maintained on a thermostatic heating pad during the entire anaesthesia period so as to maintain core body temperature. Inveon Acquisition Workplace software (Siemens) was used for image acquisition, whilst Cobra software (Exxim Computing Corporation, Pleasanton, CA) was used to reconstruct the $\mathrm{CT}$ images and Inveon Research Workplace software (Siemens) was used for reconstructing PET images and calculation of Standardized Uptake Values (SUV) according to manufacturers instructions. In order to calculate mean SUV in mouse lungs, Inveon Research Workplace software was used to place a 3-dimensional region of interest (ROI) in the area corresponding to the left lung or the right lung of each mouse, taking care to ensure that the ROIs were not placed in the region of the heart. The radioactivity concentration measured within the ROIs was then normalized to the amount of injected activity and the weight of the mice when calculating the SUV.

Post-mortem measurement of ${ }^{18}$ FDG uptake

Female Balb/c mice at 8-10 weeks of age were injected intravenously with 4T1-luc or RENCA-luc tumour cells $\left(2 \times 10^{5}\right.$ cells in $\left.100 \mathrm{ml}\right)$. The following day, mice began treatment with vehicle or $60 \mathrm{mg} / \mathrm{kg} /$ day sunitinib on a continuous dosing schedule. After 14 days (4T1 model) or 19 days (RENCA model), mice were starved for at least $4 \mathrm{~h}$ prior to being anaesthetized and injected via the tail vein with $0.5-2 \mathrm{Mbq}$ of ${ }^{18} \mathrm{FDG}$. This was then followed by a 90 min uptake period under continuous isofluorane anaesthesia, and thermostatic heating, before mice were culled. Lungs, blood and muscle tissue were collected, weighed and then counted immediately in a gamma counter (Perkin Elmer, Cambridge, Camb., UK). Counts were corrected to the tissue mass in order to calculate the percentage of injected dose present per gram of tissue.

In vitro cell proliferation assays

Human umbilical vein endothelial cells (HUVECs) were plated on 96 well plates at a density of 1,000 cells/well. The next day the medium was changed for M199 plus $10 \%$ fetal calf serum, supplemented with $100 \mathrm{ng} / \mathrm{ml}$ VEGF (R\&D Systems, Abingdon, Oxon., UK) and with sunitinib at the indicated concentration or vehicle $(0.1 \%$ DMSO). 4T1 cells or RENCA cells were plated on 96 well plates at a density of 1,000 cells/well. The next day the medium was changed for M199 plus $10 \%$ fetal calf serum, supplemented with sunitinib at the indicated concentration or vehicle (0.1\% DMSO). After $72 \mathrm{~h}$, cell viability was quantified using the Cell-TitreGlo cell viability reagent (Promega, Southampton, Hants., UK) according to the manufacturers instructions. The plates were read in a luminescence plate reader (PerkinElmer).

\section{Ethical approval for animal experimentation}

Ethical approval for animal experimentation was granted by: the Institute of Cancer Research Animal Ethics Committee and the Queen Mary University of London Animal Ethics Committee. All procedures were performed in accordance with UK Home Office regulations.

Statistical analysis

Statistical analysis of data was performed using Student's $t$ test, except for the analysis of the Kaplan-Maier survival data, which was performed using the Log-rank test. $P$ values below 0.05 were considered to be significant.

\section{Results}

The ability of sunitinib to enhance the seeding of metastasis is cell line dependent

Daily administration of sunitinib at a dose of $120 \mathrm{mg} / \mathrm{kg} /$ day for 7 days prior to intravenous injection of tumour 
cells has been reported to promote the growth of metastases in mice and leads to a shortening of overall survival. These data suggest that "pre-conditioning" of mice with sunitinib can promote the formation of metastases by circulating tumour cells [18]. We began our study by performing similar experiments using two syngeneic murine tumour cell lines. Balb/c mice were pre-treated for 7 days with vehicle or $120 \mathrm{mg} / \mathrm{kg} /$ day sunitinib, followed by intravenous injection of luciferase-tagged 4T1 tumour cells (4T1-luc) or luciferase-tagged RENCA tumour cells (RENCA-luc). In mice inoculated with 4T1-luc cells, sunitinib pre-treatment resulted in significantly enhanced lung tumour burden $(P=0.0007)$ and significantly shortened overall survival $(P=0.0009)$ compared to vehicle treated controls (Fig. 1a, b). However, lung tumour burden and overall survival in mice injected with RENCA-luc cells was equivalent in both the vehicle and sunitinib treated groups (Fig. 1c, d).

We next addressed whether sunitinib increases lung tumour burden by promoting the seeding of tumour cells in the lungs of mice. Balb/c mice were pre-treated for 7 days with vehicle or $120 \mathrm{mg} / \mathrm{kg} /$ day sunitinib, followed by intravenous injection of 4T1 or RENCA tumour cells that had been fluorescently labelled just prior to injection. Lungs were harvested at 2 or $24 \mathrm{~h}$ post-injection to assess the seeding of metastasis in the lungs by fluorescence microscopy. At $2 \mathrm{~h}$ post-injection, significantly more 4T1 tumour cells were counted in the lungs of sunitinib treated mice compared to vehicle controls (Fig. 1e, f). By $24 \mathrm{~h}$, the number of cells in the lungs in both treatment groups had reduced significantly, which is a well-described feature of such lung metastasis models and is due to the apoptosis of tumour cells [62]. However, even after this attrition, enhanced numbers of 4T1 tumour cells survived in the lungs of sunitinib pre-treated mice, compared to vehicle controls at the $24 \mathrm{~h}$ time point (Fig. 1e). In contrast, assessment of RENCA cells in the lungs of mice revealed no significant difference in cell numbers between vehicle and sunitinib pre-treated mice at either time point (Fig. 1g, h). These data indicate that sunitinib can increase lung tumour burden by promoting the seeding of metastasis, but that this effect is cell line dependent.

Reduced pericyte coverage in the lung microvasculature is associated with enhanced seeding of metastasis

Lung tissue sections obtained from the previous experiment were stained for the vessel marker CD31 and the pericyte marker NG2. Careful examination of these tissue sections revealed that, at both 2 and $24 \mathrm{~h}$ post-injection of tumour cells, 4T1 cells remained trapped as tumour emboli within the lung microvasculature in both vehicle and sunitinib pre-treated mice (for example see Fig. 2a). These data are consistent with previous work showing that 4T1 tumour cells form intravascular colonies in the lungs of mice and that extravasation occurs only when micrometastatic foci outgrow the vessels they are in [63]. We noted also that pericyte coverage of the microvasculature was clearly reduced in the lungs of sunitinib pre-treated mice compared to vehicle controls (for example see Fig. 2a, b). We then examined the relationship between pericyte coverage and the seeding of 4T1 tumour cells. First, quantification of overall pericyte coverage in the lung microvasculature revealed that pericyte coverage overall was significantly reduced in the lungs of sunitinib treated mice compared to vehicle controls at both time points (Fig. 2c, d). Second, we quantified pericyte coverage specifically in vessels that contained tumour cell emboli. In vehicle pre-treated mice, vessels containing 4T1 tumour cell emboli had significantly reduced pericyte coverage compared to the mean overall pericyte coverage of the lung microvasculature (Fig. 2c, d). Indeed, the pericyte coverage in these embolised vessels was equivalent to the mean overall pericyte coverage observed in the lungs of sunitinib pre-treated mice (Fig. 2c, d). In parallel, examination of lungs from mice injected with RENCA tumour cells revealed that RENCA tumour cell emboli were also preferentially localised to vessels with lower pericyte coverage (Fig. 2e). However, the difference between overall pericyte coverage and pericyte coverage of embolised vessels was less marked for RENCA cells than it was for 4T1 cells (compare Fig. 2d with Fig. 2e). These data show that sunitinib can deplete pericyte coverage in the lung microvasculature and that $4 \mathrm{~T} 1$ emboli, but to a lesser extent RENCA emboli, preferentially seed in the lungs at sites of reduced pericyte coverage.

\section{Enhanced seeding of metastasis is sunitinib} dose-dependent

The dose of $120 \mathrm{mg} / \mathrm{kg} /$ day sunitinib which increased lung tumour burden here, and in a previous study [18], is a relatively high dose considering that doses in the range of 20-60 mg/kg/day sunitinib are typically sufficient to suppress tumour growth and extend survival in tumour bearing mice $[17,33,41]$. We therefore proceeded to examine the outcome when mice were pre-treated with lower sunitinib doses. Balb/c mice were pre-treated for 7 days with 30, 60 or $120 \mathrm{mg} / \mathrm{kg} /$ day sunitinib or vehicle alone, followed by intravenous injection of 4T1-luc cells. Histological examination of the lungs at $24 \mathrm{~h}$ post-inoculation demonstrated significantly enhanced seeding of 4T1 cells in mice pretreated with $120 \mathrm{mg} / \mathrm{kg} /$ day sunitinib compared to vehicle controls, but not in mice pretreated with 30 or $60 \mathrm{mg} / \mathrm{kg}$ / day (Fig. 3a). In concordance with this finding, we 

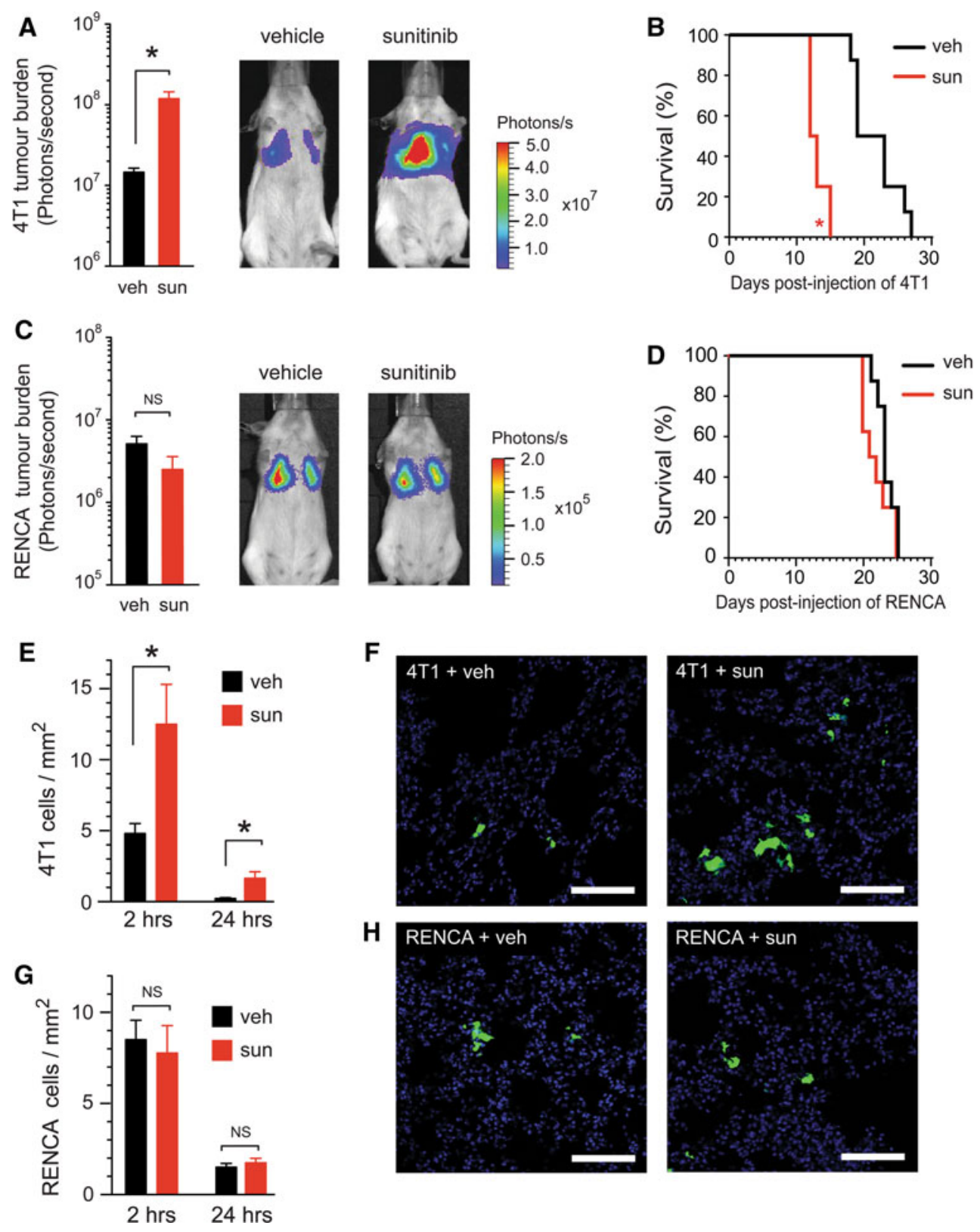

Fig. 1 The ability of sunitinib to enhance the seeding of metastasis is cell line dependent. a-d Quantification of tumour burden and survival. Balb/c mice were pre-treated with vehicle (veh) or $120 \mathrm{mg} / \mathrm{kg} /$ day sunitinib (sun) every day for 7 days, followed by intravenous injection of luciferase-tagged 4T1 tumour cells (4T1-luc) or luciferase-tagged RENCA tumour cells (RENCA-luc). In a and c, bar graphs show bioluminescence signal \pm SEM at 12 days post tumour cell injection in 4T1-luc (a) or RENCA-luc (c) tumour bearing mice. Representative bioluminescence images of mice at 12 days post tumour cell injection are also shown. $* P=0.0007$, $\mathrm{n}=8$ mice per treatment group. In $\mathbf{b}$ and $\mathbf{d}$, Kaplan-Meier analysis of overall survival in 4T1-luc (b) or RENCA-luc (d) tumour bearing

observed significantly reduced pericyte coverage in the lungs of mice pretreated with $120 \mathrm{mg} / \mathrm{kg} / \mathrm{day}$ sunitinib compared to vehicle controls, but not in mice pretreated with 30 or $60 \mathrm{mg} / \mathrm{kg} /$ day sunitinib (Fig. 3b). Bioluminescence mice is shown. ${ }^{*} P=0.0009, \mathrm{n}=8$ mice per treatment group. $\mathrm{e}-$ h Quantification of tumour cell seeding in the lungs. Balb/c mice were pre-treated with vehicle (veh) or $120 \mathrm{mg} / \mathrm{kg} /$ day sunitinib (sun) every day for 7 days, followed by intravenous injection of fluorescently labeled 4T1-luc or RENCA-luc cells. In e and $\mathbf{g}$, bar graphs show number of tumour cells counted per $\mathrm{mm}^{2}$ of lung tissue section \pm SEM at 2 and $24 \mathrm{~h}$ after injection of 4T1-luc (e) or RENCAluc $(\mathrm{g})$. $* P=0.02, \mathrm{n}=8$ mice per treatment group. Representative images of lung sections from 4T1-luc (f) or RENCA-luc (h) tumour bearing mice are also shown, tumour cells (green) and DAPI (blue). Scale bar $=100 \mu \mathrm{M}$. NS $=$ no significant difference. (Color figure online)

imaging revealed that although lung tumour burden in mice pretreated with $120 \mathrm{mg} / \mathrm{kg} /$ day sunitinib was significantly increased compared to vehicle-treated controls at $24 \mathrm{~h}$ $(P=0.01)$ and 12 days $(P=0.002)$ after tumour cell 
A
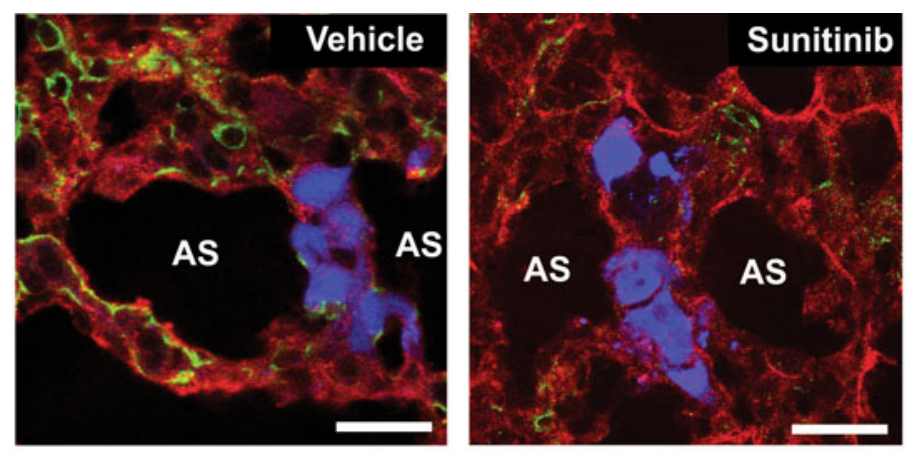

B
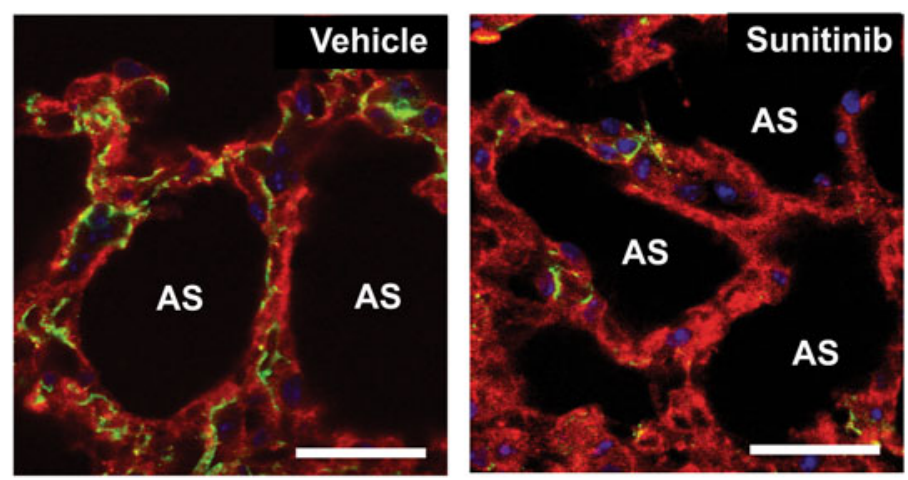

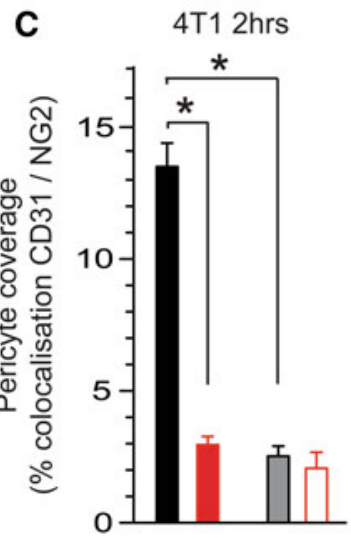

Vehicle (overall pericyte coverage)

Sunitinib (overall pericyte coverage)
D

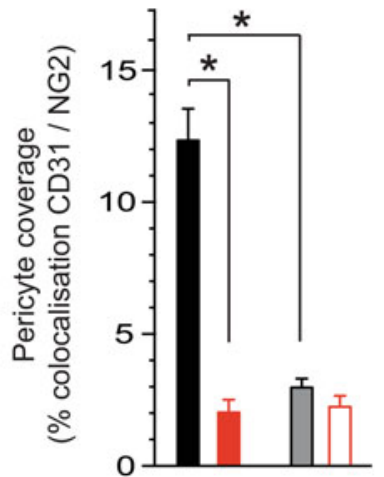

E

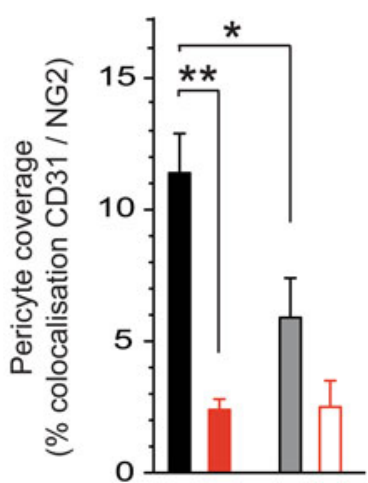

Fig. 2 Reduced pericyte coverage in the lung microvasculature is associated with enhanced seeding of metastasis. Balb/c mice were pre-treated with vehicle (veh) or $120 \mathrm{mg} / \mathrm{kg} /$ day sunitinib (sun) every day for 7 days, followed by intravenous injection of fluorescently tagged 4T1-luc or RENCA-luc tumour cells. Lungs were harvested at 2 or $24 \mathrm{~h}$ post-injection of tumour cells and sections were stained for the vessel marker CD31 and the pericyte marker NG2. a Representative images of $4 \mathrm{~T} 1$ tumour cell emboli trapped within the lung vasculature at $24 \mathrm{~h}$ post-injection of tumour cells in mice pre-treated with vehicle or sunitinib as indicated, tumour cells (blue), CD31 (red) and NG2 (green). b Representative images of pericyte coverage within the lung vasculature at $24 \mathrm{~h}$ post-injection of $4 \mathrm{~T} 1$ tumour cells in mice pre-treated with vehicle or sunitinib as indicated, CD31 (red),

injection, tumour burden in the lungs of mice pretreated with 30 or $60 \mathrm{mg} / \mathrm{kg} /$ day sunitinib was not statistically different to vehicle treated mice at either time point
Vehicle (pericyte coverage of embolised vessels)

Sunitinib (pericyte coverage of embolised vessels)

NG2 (green) and DAPI (blue). c, d Quantification of overall pericyte coverage in the lung vasculature and pericyte coverage only in vessels containing 4T1 tumour cell emboli. Data are shown at $2 \mathrm{~h} \mathrm{(c)} \mathrm{and}$ $24 \mathrm{~h} \mathrm{(d)} \mathrm{post-injection} \mathrm{of} \mathrm{tumour} \mathrm{cells} \mathrm{in} \mathrm{mice} \mathrm{pre-treated} \mathrm{with}$ vehicle or sunitinib. Bar graph shows percentage colocalisation between CD31 and NG2 \pm SEM. $* P=0.0001, \mathrm{n}=8$ mice per treatment group. e Quantification of overall pericyte coverage in the lung vasculature and pericyte coverage only in vessels containing RENCA tumour cell emboli. Data are shown at $24 \mathrm{~h}$ post-injection of tumour cells in mice pre-treated with vehicle or sunitinib. Bar graph shows percentage colocalisation between CD31 and NG2 \pm SEM. $* P=0.03, * * P=0.0001 . \mathrm{n}=8$ mice per treatment group. Scale bar $=25 \mu \mathrm{M}, \mathrm{AS}=$ alveolar space. (Color figure online)

(Fig. 3c). In terms of overall survival, in mice pretreated with $120 \mathrm{mg} / \mathrm{kg} /$ day sunitinib we again observed shortened survival compared to vehicle (median survival 12 days vs. 

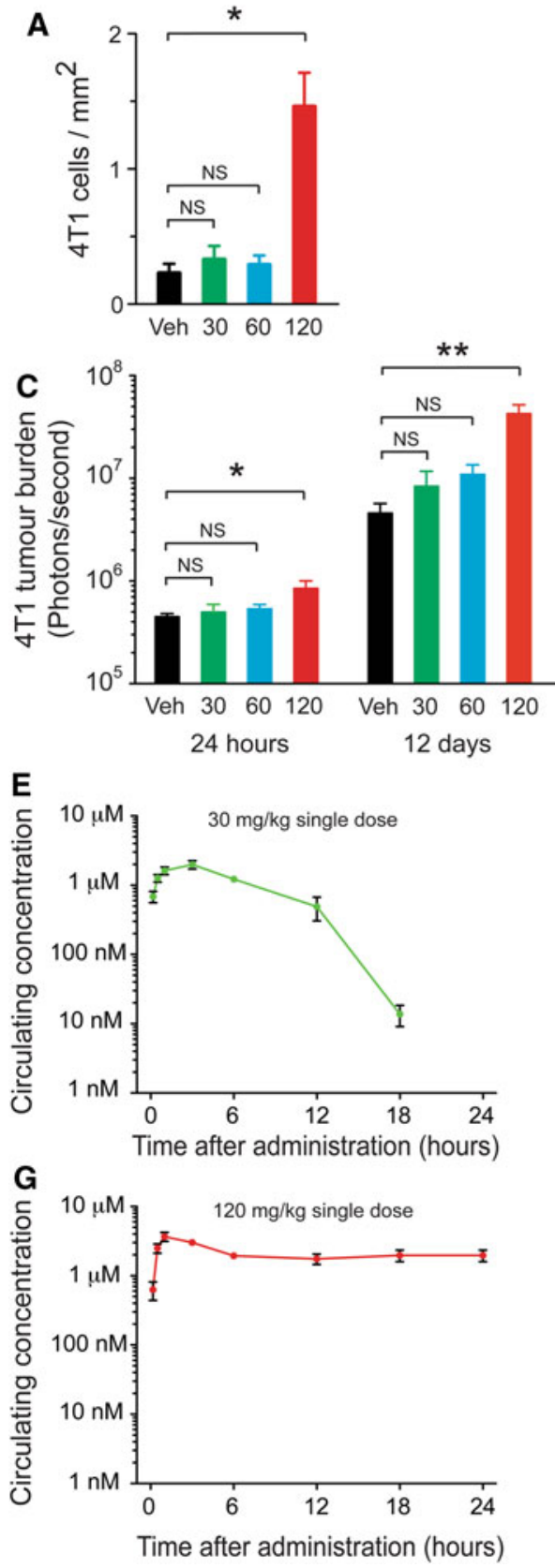

Fig. 3 Enhanced seeding of metastasis is sunitinib dose-dependent. a-d Dose-dependent effects of sunitinib. Balb/c mice were pre-treated with 30,60 or $120 \mathrm{mg} / \mathrm{kg} /$ day sunitinib or vehicle for 7 days, followed by intravenous injection of 4T1-luc tumour cells. a Quantification of tumour cells seeded in the lung at $24 \mathrm{~h}$ post tumour cell injection in mice pre-treated with the indicated dose of sunitinib. Bar graph shows number of cells counted per $\mathrm{mm}^{2}$ of lung tissue section \pm SEM. $* P=0.01, \mathrm{n}=8$ mice per treatment group. b Quantification of pericyte coverage in the normal lung vasculature at $24 \mathrm{~h}$ post-injection of tumour cells in mice pre-treated with the indicated dose of sunitinib. Bar graph shows percentage colocalisation between CD31 and NG2 \pm SEM. $* P=0.0001, \mathrm{n}=8$ mice per treatment group. c Bioluminescence signal at 1 day or 12 days post tumour cell injection in mice pre-treated with the indicated dose of sunitinib $\pm \mathrm{SEM}, \quad * P=0.01, \quad * * P=0.002, \quad \mathrm{n}=8$ mice per
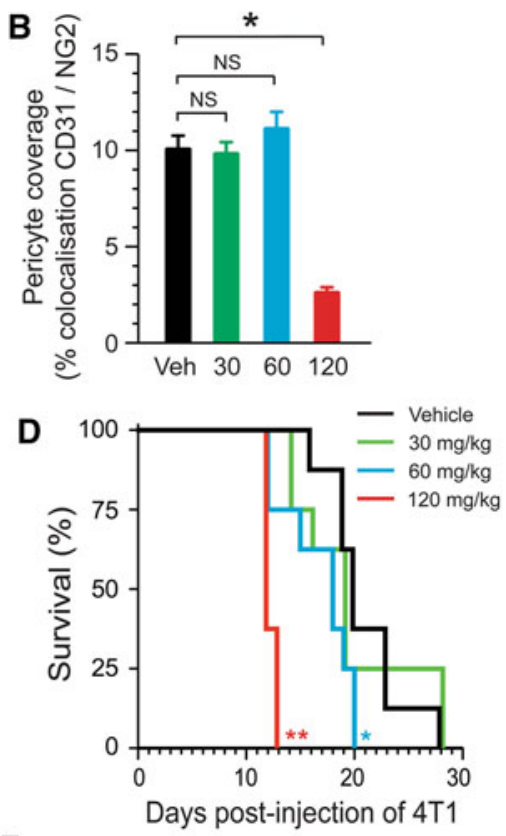

$\mathbf{F}$
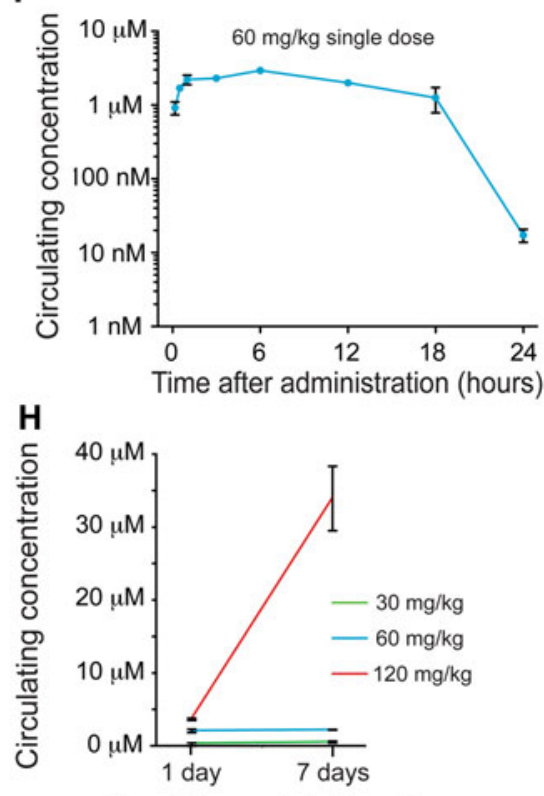

No. of days administered

treatment group. d Kaplan-Meier analysis of overall survival is shown in mice pre-treated with the indicated dose of sunitinib. $* P=0.03, * * P=0.0001, \mathrm{n}=8$ mice per group. $\mathbf{e}-\mathbf{h}$ Pharmacokinetics of sunitinib. Balb/c mice were administered a single oral dose of $30 \mathrm{mg} / \mathrm{kg}(\mathbf{e}), 60 \mathrm{mg} / \mathrm{kg}$ (f) or $120 \mathrm{mg} / \mathrm{kg}$ (g) sunitinib. At the indicated times after dosing, blood samples were collected and the plasma concentration of sunitinib was determined. $n=4$ mice per time point. $\mathbf{h ~ B a l b / c ~ m i c e ~ w e r e ~ a d m i n i s t e r e d ~ a ~ s i n g l e ~ d o s e ~ o f ~ s u n i t i n i b ~}$ at 30,60 or $120 \mathrm{mg} / \mathrm{kg}$ or were administered sunitinib at 30,60 or $120 \mathrm{mg} / \mathrm{kg}$ every day for 7 days. At $12 \mathrm{~h}$ after administration of a single sunitinib dose, or at $12 \mathrm{~h}$ after administration of the seventh dose of sunitinib, blood samples were collected and the plasma concentration of sunitinib was determined. $n=4$ mice per time point, $\mathrm{NS}=$ no significant difference 
20 days, $P=0.0001$, Fig. $3 \mathrm{~d}$ ). Survival was also shortened, albeit to a lesser extent, by pre-treatment with $60 \mathrm{mg} / \mathrm{kg} / \mathrm{day}$ sunitinib compared to vehicle (median survival 18 days vs. 20 days, $P=0.03$, Fig. 3 d), but pre-treatment with $30 \mathrm{mg} /$ $\mathrm{kg}$ /day sunitinib did not significantly shorten survival compared to vehicle (median survival 19 days vs. 20 days; $P=0.7$, Fig. 3d).

We then examined the pharmacokinetics of sunitinib when administered at different doses (Fig. 3e-g). All three doses $\left(30,60\right.$ and $120 \mathrm{mg} / \mathrm{kg}$ ) achieved a similar $\mathrm{C}_{\max }$ of $\geq 2 \mu \mathrm{M}$ within a few hours of administration to mice. However, the clearance of sunitinib was markedly different for the three doses. Whilst clearance of drug began at $8 \mathrm{~h}$ post-administration in mice treated with $30 \mathrm{mg} / \mathrm{kg}$ sunitinib and dipped below the limit of detection by $24 \mathrm{~h}$ (Fig. 3e), clearance in mice treated with $60 \mathrm{mg} / \mathrm{kg}$ sunitinib was less efficient (Fig. 3f). Importantly, in mice treated with $120 \mathrm{mg} / \mathrm{kg}$ sunitinib, no significant clearance was evident even after $24 \mathrm{~h}$ (Fig. 3g). We then addressed whether the inefficient clearance of sunitinib observed at higher doses could result in elevated circulating levels of sunitinib after prolonged dosing. After 7 days treatment with $120 \mathrm{mg} / \mathrm{kg} /$ day sunitinib, circulating concentrations of drug were elevated to $\sim 30 \mu \mathrm{M}$, whereas no such increase was observed in mice treated for 7 days with 30 or $60 \mathrm{mg} /$ $\mathrm{kg}$ /day sunitinib (Fig. 3h). These data suggest that the enhanced seeding of metastasis induced by sunitinib occurs only when mice are exposed to sustained micromolar circulating concentrations of the drug.

Contrasting outcomes in mice administered sunitinib after tumour cell seeding in the lungs

We then proceeded to examine tumour growth and outcome when sunitinib was administered after intravenous inoculation of tumour cells. Balb/c mice were injected intravenously with 4T1-luc or RENCA-luc tumour cells. After $24 \mathrm{~h}$, these mice then commenced treatment with vehicle or sunitinib. Mice were administered sunitinib at different doses and under various schedules (see Fig. 4a). We tested short term therapy with 30,60 or $120 \mathrm{mg} / \mathrm{kg} /$ day sunitinib, where drug was administered daily for 1 week only. We also tested continuous therapy where mice were administered daily with 30 or $60 \mathrm{mg} / \mathrm{kg} / \mathrm{day}$ sunitinib until they became moribund. In addition we tested treatment for 7 days with $120 \mathrm{mg} / \mathrm{kg} / \mathrm{day}$ sunitinib, followed by switching to continuous therapy with $60 \mathrm{mg} / \mathrm{kg} /$ day sunitinib which was administered until mice became moribund (120-60 schedule). Importantly, none of these dosing regimes were capable of extending overall survival in $4 \mathrm{~T} 1$ tumour bearing mice (Fig. $4 \mathrm{~b}, \mathrm{c}$ ). Indeed, significantly shortened overall survival compared to vehicle controls was observed in mice receiving short term therapy with $120 \mathrm{mg} / \mathrm{kg} /$ day sunitinib (median survival 20 days vs.
23 days; $P=0.003$ ), continuous therapy with $60 \mathrm{mg} / \mathrm{kg} /$ day sunitinib or the 120-60 schedule (median survival 18 days vs. 23 days; $P=0.003$ ). In contrast, sunitinib was able to significantly extend survival compared to vehicle controls in RENCA tumour bearing mice (Fig. 4d). Continuous dosing was particularly effective in the RENCA model, with median survival extended to 33 days or beyond, compared to a median survival of 23 days in vehicle-treated mice (Fig. 4d). These data show that whilst sunitinib can shorten overall survival in 4T1 tumour bearing mice, the same drug can extend survival in RENCA tumour bearing mice.

To examine the effect of sunitinib treatment on tumour growth in the two metastasis models, lung tumour burden was examined using three methods: in vivo bioluminescence imaging, weighing freshly resected lungs and quantitative histology of lung sections. We chose to use continuous therapy with $60 \mathrm{mg} / \mathrm{kg} /$ day sunitinib, because this regimen gave rise to the most contrasting difference in responses i.e. significantly shortened overall survival in the 4T1 model (Fig. 4c) and significantly increased overall survival in the RENCA model (Fig. 4d). Surprisingly, lung tumour burden in sunitinib treated mice was not significantly different from vehicle treated controls in the 4T1 model (Fig. 5a-d). By contrast, in the RENCA model, sunitinib treatment resulted in significantly decreased lung tumour burden compared to vehicle controls (Fig. 5e-h). Therefore, while sunitinib fails to inhibit the growth of 4T1 tumours after they have seeded in the lungs of mice, sunitinib can significantly suppress the growth of RENCA tumours.

Since sunitinib is a relatively broad spectrum tyrosine kinase inhibitor, it could potentially target both the tumour vasculature and tumour cell proliferation directly [29]. Therefore, we examined the sensitivity of 4T1 and RENCA cells to sunitinib in vitro (Fig. 6). The IC50 for both cell lines was relatively high and very similar, with 4T1 cells (IC50 $=3 \mu \mathrm{M})$ being marginally more sensitive to sunitinib than RENCA cells (IC50 $=5 \mu \mathrm{M}$ ). As a positive control for sunitinib activity, we show that VEGF-induced proliferation of endothelial cells is 2 orders of magnitude more sensitive to sunitinib than the tumour cell lines (IC50 $=10 \mathrm{nM}$, Fig. 6). These data suggest that the superior efficacy of sunitinib in the RENCA model compared to the 4T1 model is not due to direct inhibition of RENCA cell proliferation by sunitinib.

Analysis of microvessel density and hypoxia in lung metastases treated with sunitinib

We then addressed the effect of sunitinib on tumour angiogenesis and tumour hypoxia. Mice were injected intravenously with 4T1-luc or RENCA-luc cells and then commenced treatment with vehicle or $60 \mathrm{mg} / \mathrm{kg} / \mathrm{day}$ 
Fig. 4 Survival of mice treated with sunitinib after intravenous injection of tumour cells.

a Schematic diagram of dosing schedules tested. Balb/c mice were injected intravenously with 4T1-luc or RENCA-luc tumour cells and then treated with vehicle, 30,60 or $120 \mathrm{mg} /$ $\mathrm{kg} /$ day sunitinib daily for only 7 days (short term therapy) or daily until they became moribund (continuous dosing schedule). b, c Kaplan-Meier analysis of survival for 4T1-luc tumour bearing mice treated with vehicle or sunitinib under the dosing schedules shown in a. The two graphs show results from the same experiment, but survival of mice treated with sunitinib for 7 days (b) or treated with sunitinib continuously (c) have been presented as separate graphs for clarity. $* P=0.003, \mathrm{n}=8$ mice per treatment group. d KaplanMeier analysis of survival for RENCA-luc tumour bearing mice treated with vehicle or sunitinib under the dosing schedules shown in

a. ${ }^{*} P=0.01, * * P=0.0004$, $* * * P=0.0001, \mathrm{n}=8$ mice per treatment group
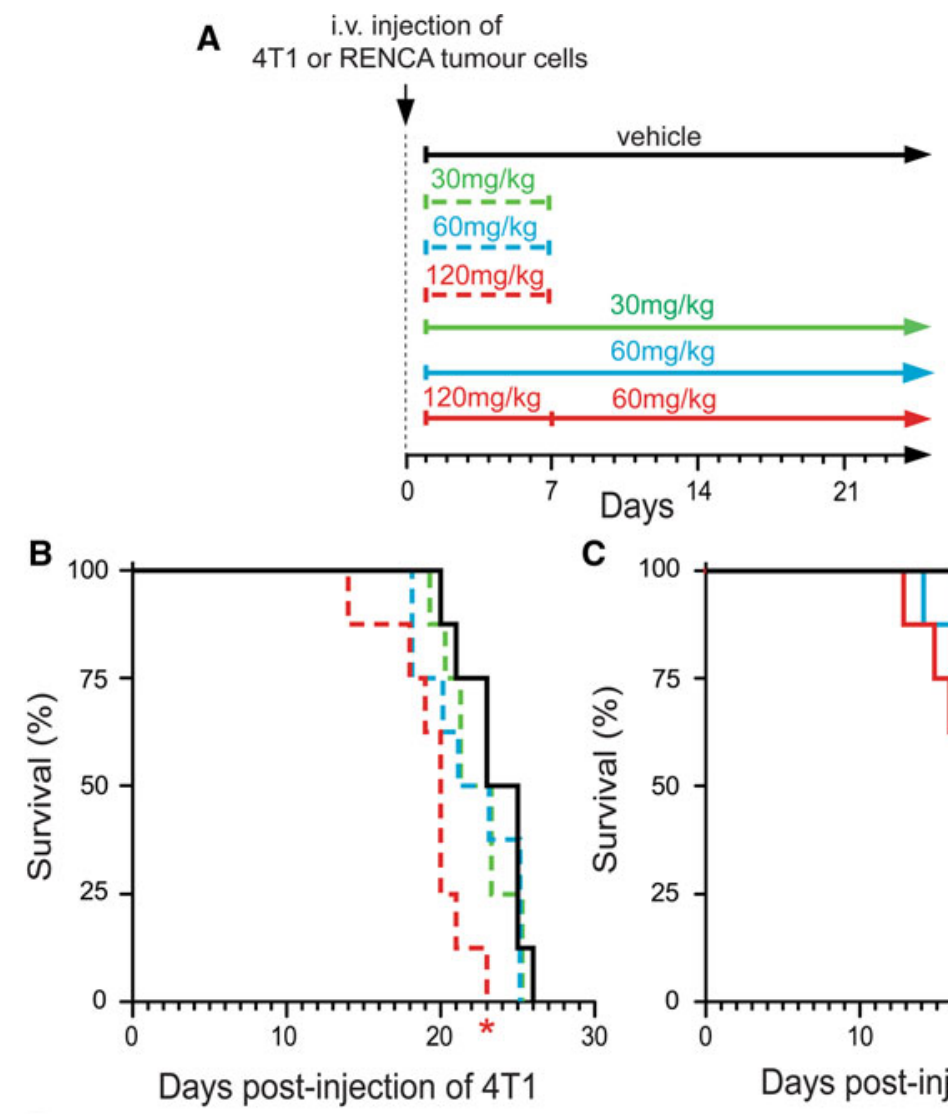

C 100

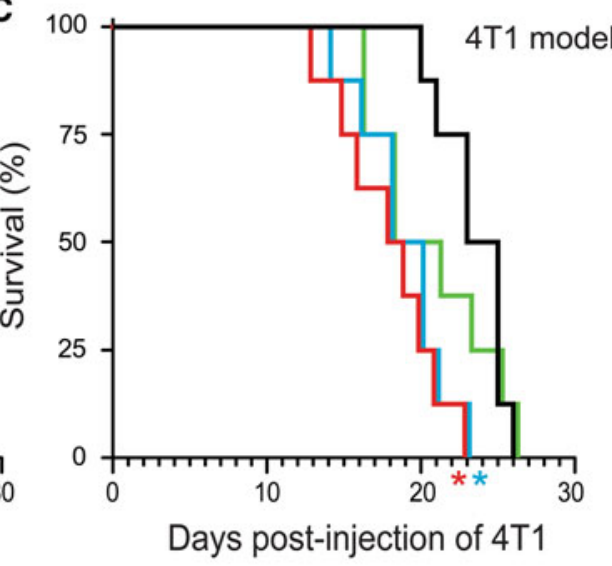

D

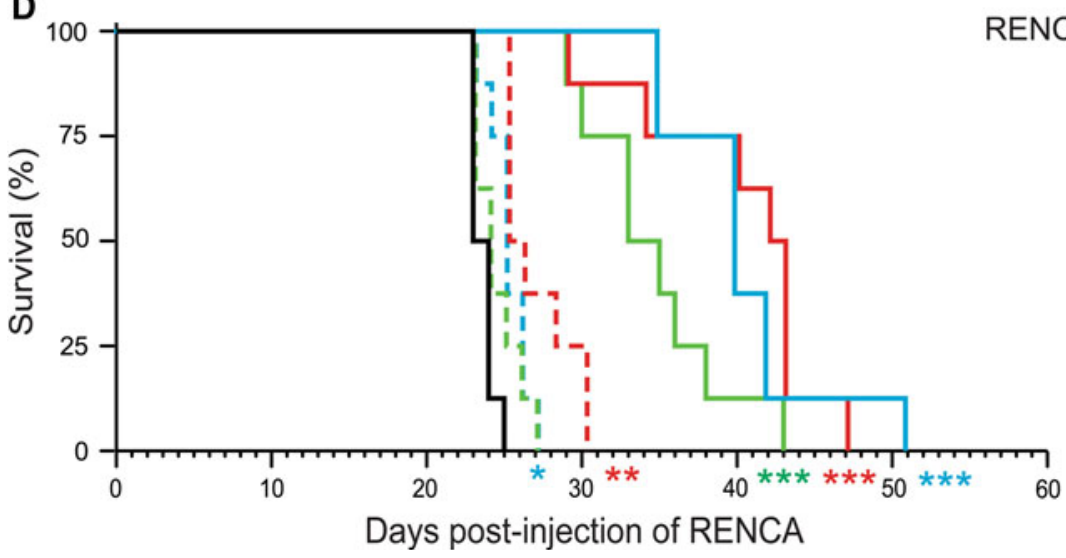

sunitinib. After 2 weeks of treatment, lungs were harvested for histological examination. Staining for CD31 was used to assess tumour microvessel density (MVD) and the hypoxia probe pimonidazole hydrochloride was used to assess tumour hypoxia (Fig. 7a-c). Intratumoural vessels were present in both the 4T1 and RENCA lung tumour nodules, although MVD in the 4T1 tumour nodules was $\sim 25 \%$ higher than in RENCA tumours $(P=0.015)$. Importantly, sunitinib treatment led to a significant reduction in MVD in both the 4T1 and RENCA lung tumour nodules compared to the corresponding vehicle control tumours $(P=0.0003$ for $4 \mathrm{~T} 1, P=0.0004$ for RENCA, Fig. 7b). However, sunitinib had a more profound effect on angiogenesis in the RENCA model than the 4T1 model. Whilst sunitinib treated RENCA tumours were reduced in MVD by $\sim 70 \%$ compared to vehicle controls, a reduction of only $\sim 50 \%$ was observed in the $4 \mathrm{~T} 1$ model. In concordance with this, a significant difference between the MVD in sunitinib treated RENCA tumours and sunitinib treated 4T1 tumours was observed ( $P=0.008$, Fig. $7 \mathrm{~b}$ ).

Quantification of pimonidazole staining demonstrated that hypoxia was significantly increased in 4T1 tumours in sunitinib treated mice compared to vehicle treated controls $(P=0.001$, Fig. 7a, c). Moreover, the 4T1 tumours that grew in sunitinib treated-mice typically consisted of two distinct zones. A well-vascularised zone of tumour cells 

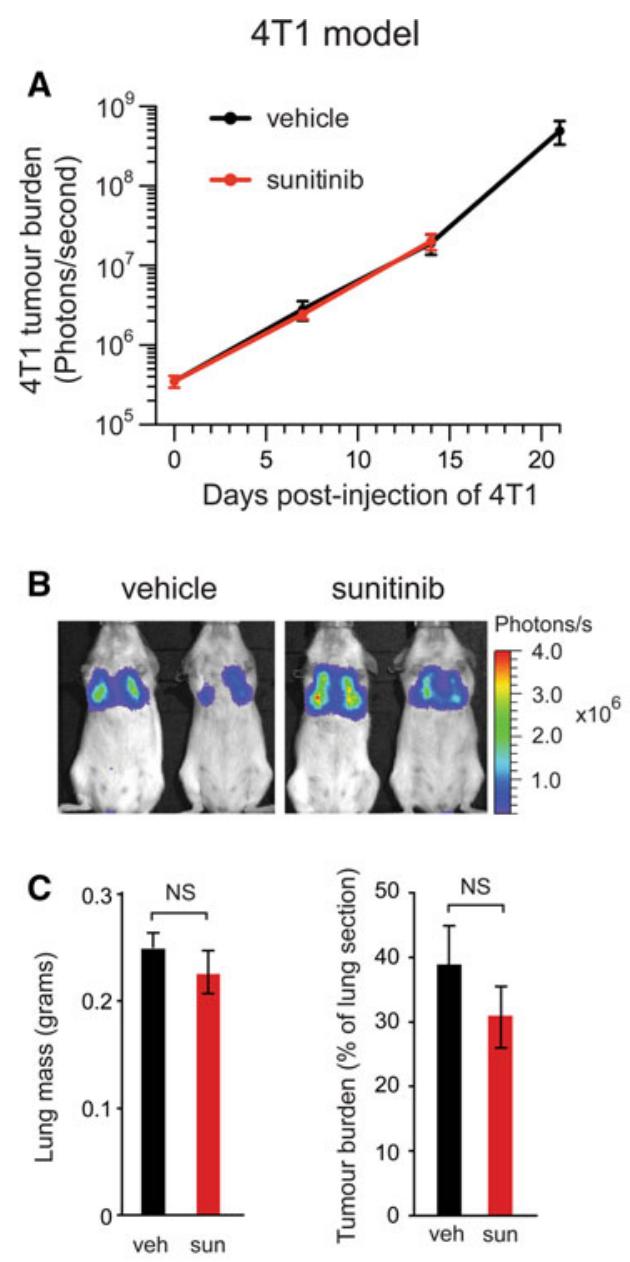

D

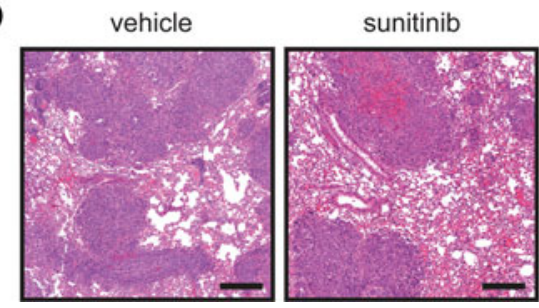

Fig. 5 Lung tumour burden in mice treated with sunitinib after intravenous injection of tumour cells. Balb/c mice were injected intravenously with 4T1-luc or RENCA-luc tumour cells and then treated with daily vehicle (veh) or $60 \mathrm{mg} / \mathrm{kg} / \mathrm{day}$ sunitinib (sun) on a continuous dosing schedule. a, e Lung tumour burden was quantified in 4T1-luc (a) or RENCA-luc (e) tumour bearing mice. Graphs show bioluminescence signal at the indicated time points after injection of tumour cells \pm SEM. Note that the difference in duration over which bioluminescence is monitored for each experimental group is due to the difference in the overall survival observed in each group. $* P=0.02,{ }^{*} * P=0.004, \mathrm{n}=8$ mice per treatment group. $\mathbf{b}$, f Representative bioluminescence images of 4T1-luc (b) or

was present around the rim of the tumours and a poorlyvascularised zone composed of pimonidazole-positive cells and necrotic tumour cells was present at the centre of the tumours (Fig. 7d, left hand image). These pimonidazolepositive regions also stained strongly positive for CAIX
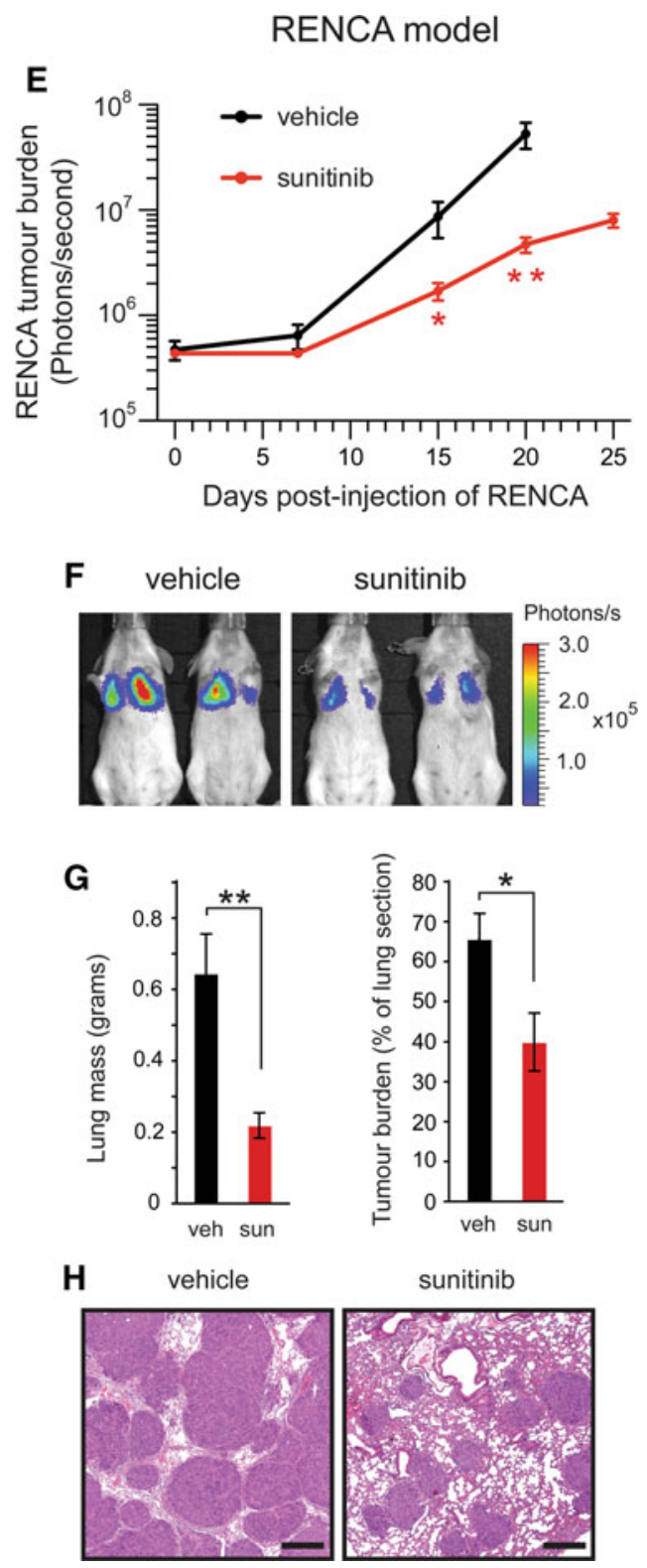

RENCA-luc (f) tumour bearing mice at 14 days (4T1-luc) or 15 days (RENCA-luc) after tumour cell injection. $\mathbf{c}, \mathbf{g}$ Tumour burden was quantified in 4T1-luc (c) or RENCA-luc (g) tumour bearing mice at 14 days (4T1-luc) or 18 days (RENCA-luc) after tumour cell injection by weighing lungs or by quantitative histology. Graphs show lung mass \pm SEM or percentage area of lung section occupied by tumour \pm SEM. $* P=0.01, * * P=0.0001, \mathrm{n}=8$ mice per treatment group. d, h Representative fields of $H \& E$ stained sections of lung from 4T1-luc (d) or RENCA-luc (h) tumour bearing mice at 14 days (4T1-luc) or 18 days (RENCA-luc) after tumour cell injection. Scale bar $=400 \mu \mathrm{M}$, NS $=$ no significant difference

and GLUT-1 (Fig. 7e, f), markers that are synonymous with increased tumour hypoxia and increased tumour glucose metabolism [3, 8]. This observation is consistent with previous reports showing that impairment of vascular function caused by inhibition of VEGF signalling can lead 


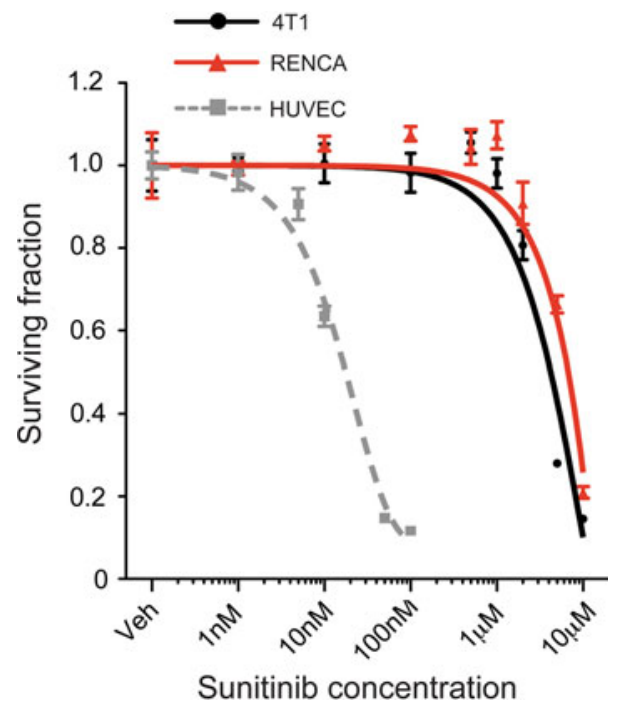

Fig. 6 Effect of sunitinib on tumour cell viability. a The ability of 4T1 tumour cells, RENCA tumour cells or primary endothelial cells (HUVECs), to proliferate in the presence of sunitinib was measured in vitro. Graphs show the surviving fraction of cells after $72 \mathrm{~h} \pm$ SEM

to increased tumour hypoxia and the induction of hypoxiaassociated genes [14, 27]. In contrast, hypoxia was not exacerbated in RENCA tumours in sunitinib-treated mice (Fig. 7a, c). Measurement of lesion diameters (see Table 1) revealed that RENCA lesions in the sunitinib treatment group were on average half the size of $4 \mathrm{~T} 1$ lesions in sunitinib treated mice $(464 \pm 22 \mu \mathrm{m}$ vs. $1,142 \pm 48 \mu \mathrm{m})$. Since the diffusion limit of oxygen in vivo is estimated to be within the range of 200-250 $\mu$ [59] the RENCA lesions in sunitinib treated mice are likely to receive adequate oxygenation from the surrounding lung parenchyma, which may explain the lack of increased hypoxia in these RENCA tumours.

Analysis of pericyte coverage and myeloid cell recruitment in lung metastases treated with sunitinib

Since sunitinib is a potent inhibitor of PDGF receptor signalling [1], and signalling by PDGF is an important mediator of pericyte recruitment during tumour angiogenesis [4], we examined pericyte coverage in each experimental group. Similar levels of pericyte coverage were observed in 4T1 and RENCA tumours from vehicle treated mice (Fig. 8a, b). However, sunitinib treatment resulted in a significant reduction in pericyte coverage of $\sim 50 \%$ in both tumour models (Fig. 8a, b). Therefore, we did not observe contrasting effects of sunitinib on pericyte coverage in 4T1 and RENCA tumours.

The ability of tumours to recruit and retain pro-angiogenic Gr1+CD11b+ myeloid cells has been implicated in both the induction of tumour angiogenesis [65] and in mediating resistance to anti-angiogenic therapies [54]. By co-staining sections of lung tissue with both Gr1- and CD11b-specific antibodies, we were able to identify myeloid cells within the tumour nodules that labeled positive for both Gr1 and CD11b (Fig. 8c). We then addressed whether the recruitment of these $\mathrm{Gr} 1+\mathrm{CD} 11 \mathrm{~b}+$ myeloid cells differed between experimental groups. Moreover, by co-staining for CD31, we examined the proximity of these cells to intratumoural blood vessels. Significantly more $\mathrm{Gr} 1+\mathrm{CD} 11 \mathrm{~b}+$ myeloid cells were present in $4 \mathrm{~T} 1$ tumour nodules compared to RENCA tumours in both the presence and absence of sunitinib (Fig. 8d, e). These differences were not a function of tumour size, since we sampled 4T1 and RENCA tumours of a similar size range in order to determine these data. Interestingly, whilst Gr1+CD11b+ myeloid cells were typically colocalised with CD31 positive blood vessels in 4T1 tumours, this colocalisation was absent in RENCA tumours (Fig. 8e). These data suggest that 4T1 and RENCA lung metastases differ in their ability to recruit and retain pro-angiogenic myeloid cells, and that their capacity to recruit these cells is unaffected by sunitinib treatment.

Measurement of glucose uptake in the lungs of tumour bearing mice treated with sunitinib

Markers associated with increased hypoxia and increased glucose metabolism were both elevated in 4T1 lung tumour nodules in sunitinib treated mice (see Fig. 7). We therefore addressed whether a functional increase in glucose metabolism was also observed in these 4T1 tumours. $\mathrm{Balb} / \mathrm{c}$ mice were injected intravenously with 4T1-luc or RENCA-luc tumour cells and then commenced continuous treatment with vehicle or $60 \mathrm{mg} / \mathrm{kg} /$ day sunitinib. Glucose metabolism was assessed using both in vivo ${ }^{18} \mathrm{FDG}-\mathrm{PET} /$ CT imaging and ex vivo quantification of ${ }^{18} \mathrm{FDG}$ uptake. The presence of multiple tumour nodules in the lungs of the mice prevented us from assessing ${ }^{18} \mathrm{FDG}$ uptake within individual lesions. Instead, tumour glucose uptake was quantified in a semi-quantitative fashion by measuring glucose uptake in the entire lung. In the 4T1 model, the uptake of ${ }^{18}$ FDG in the lungs of sunitinib treated mice was significantly increased compared to vehicle treated mice at 14 days after injection of tumour cells (Fig. 9a-c). In contrast, the uptake of ${ }^{18}$ FDG was significantly suppressed in the lungs of RENCA tumour bearing mice treated with sunitinib compared to vehicle controls (Fig. 9d-f). Since no significant difference in tumour burden between vehicle and sunitinib treated mice is observed in the 4T1 model (for example see Fig. 5a-d), the difference in ${ }^{18}$ FDG uptake measured is most likely due to increased glucose metabolism occurring in the 4T1 lung tumour nodules of sunitinib treated mice. 

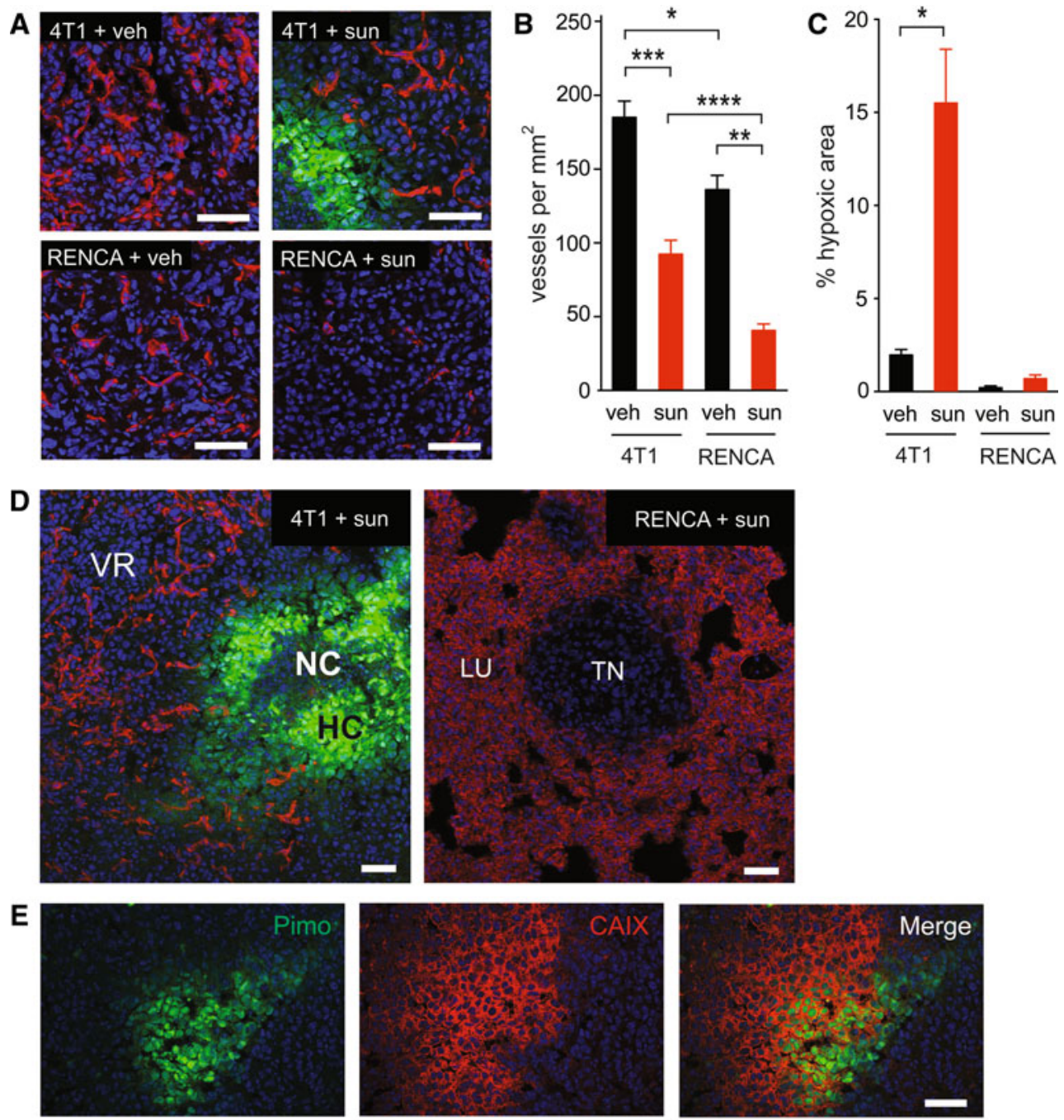

$\mathbf{F}$
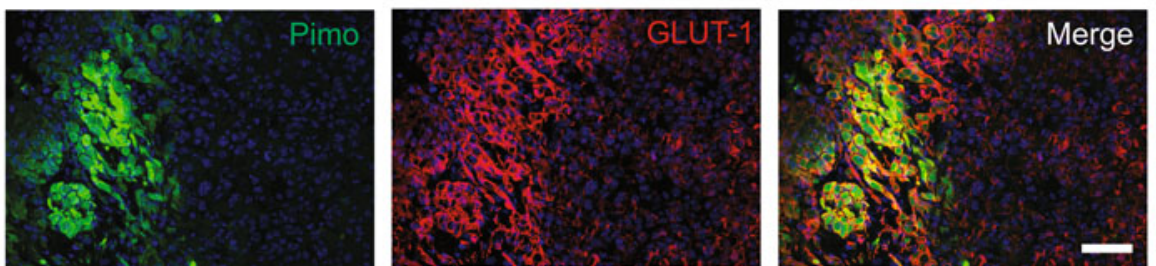

Fig. 7 Quantification of tumour vascularisation and tumour hypoxia. $\mathrm{Balb} / \mathrm{c}$ mice were injected intravenously with $4 \mathrm{~T} 1$ or RENCA cells and then treated with vehicle (veh) or $60 \mathrm{mg} / \mathrm{kg} /$ day sunitinib (sun) for 14 days, at which time point mice were culled and lungs were collected for histological analysis. a Representative fields of CD31 (red), pimonidazole (green) and DAPI (blue) staining in 4T1 and RENCA tumour nodules from vehicle or sunitinib treated mice as indicated. b Quantification of microvessel density in tumour nodules. Graph shows number of vessels per $\mathrm{mm}^{2} \pm$ SEM. $* P=0.015$, $* * P=0.008, * * * P=0.0003, * * * * P=0.0004, \mathrm{n}=8$ mice per treatment group. $\mathbf{c}$ Quantification of pimonidazole staining in tumour

\section{Discussion}

Therapeutic targeting of the VEGF signalling pathway can suppress tumour growth by blocking tumour angiogenesis nodules. Graph shows percentage area of the tumour nodules that stained positive for pimonidazole \pm SEM. ${ }^{*} P=0.001, \mathrm{n}=8$ mice per treatment group. d Left panel low power view of a 4T1 lung tumour nodule from a sunitinib treated mouse. Right panel low power view of a RENCA lung tumour nodule from a sunitinib treated mouse. Staining is for CD31 (red), pimonidazole (green) and DAPI (blue). $\mathrm{VR}$, vascular rim; $\mathrm{HC}$, hypoxic core; $\mathrm{NC}$, necrotic core; $\mathrm{TN}$, tumour nodule; LU, normal lung. e, f Co-staining for pimonidazole and CAIX (e) or GLUT-1 (f) in 4T1 tumours. NS = no significant difference, Scale bar $=50 \mu \mathrm{M}$. (Color figure online)

$[20,25,28]$. For example, the potent VEGF receptor tyrosine kinase inhibitor sunitinib can extend both progression free survival and overall survival in mRCC patients $[44,45]$. However, the clinical efficacy of VEGF 
Table 1 Lesion diameter in each experimental group

\begin{tabular}{llc}
\hline & \multicolumn{2}{l}{ Treatment received } \\
\cline { 2 - 3 } Cohort & Vehicle $(\mu \mathrm{m})$ & $60 \mathrm{mg} / \mathrm{kg} /$ day sunitinib $(\mu \mathrm{m})$ \\
\hline 4T1 & $1,065 \pm 51$ & $1,142 \pm 48$ \\
RENCA & $1,000 \pm 40$ & $464 \pm 22$ \\
\hline
\end{tabular}

Mice were inoculated intravenously with 4T1-luc or RENCA-luc tumour cells and then treated continuously with daily vehicle or daily $60 \mathrm{mg} / \mathrm{kg} /$ day sunitinib. After 2 weeks lungs were harvested, H\&E stained sections prepared and lesion diameters were measured microscopically. 100 lesions from each experimental group were measured. Lesion diameter in $\mu \mathrm{m} \pm$ SEM is shown. $\mathrm{n}=8$ mice per experimental group

pathway targeted agents is hindered by the existence of both intrinsic and acquired tumour resistance [7, 50]. Alarmingly, recent pre-clinical studies have shown that VEGF receptor inhibitors, including sunitinib, may paradoxically promote the growth of metastases in mice [13, $18,47,52]$. In the present study we show that the ability of sunitinib to promote the growth of metastases is both tumour cell line dependent and sunitinib dose dependent. We also confirm that metastatic disease in mice can be resistant to sunitinib and show that this resistance is associated with a poor outcome. However, in parallel we also show that sunitinib can suppress the growth of metastatic disease in mice and that this is associated with an overall survival benefit.

First we examined the ability of sunitinib to mediate a "conditioning effect" which promotes the seeding and growth of tumours at the site of metastasis. This was based on a previous study, in which treatment with sunitinib prior to intravenous injection of tumour cells was shown to promote metastasis [18]. In our study we demonstrate that not all tumour cell lines may be susceptible to this conditioning effect, since prior treatment with sunitinib only resulted in enhanced seeding of metastasis in mice inoculated with $4 \mathrm{~T} 1$ cells, but not RENCA cells. In addition, we found that the conditioning effect was only observed when mice were administered doses of sunitinib that produce sustained micromolar circulating concentrations of drug. In patients, circulating concentrations of sunitinib do not typically exceed $200 \mathrm{nM}[9,24]$. Moreover, a meta-analysis of pharmacokinetic data demonstrates that, within the clinically relevant dose exposure range, increased circulating levels of sunitinib are in fact associated with improved clinical outcome in mRCC patients, including longer time to progression and longer overall survival [31]. Sunitinib is a relatively selective receptor tyrosine kinase inhibitor at nanomolar concentrations [1, 41, 46], but at micromolar doses it is likely to exert many offtarget effects. Consequently, the observation that high dose sunitinib pre-treatment of mice can promote tumour metastasis may be of little relevance in patients.

Whilst this manuscript was under revision, another study [11] reported that sunitinib only promotes metastasis when administered to mice at high doses, which supports the findings reported here. Chung et al. suggested that micromolar doses of sunitinib can promote tumour cell extravasation in the lung by compromising endothelial cell barrier integrity. However, we did not observe enhanced extravasation of tumour cells in the lungs of mice treated with high doses of sunitinib. Instead, we found that tumour cells remained trapped as emboli in the lung vasculature, even at $24 \mathrm{~h}$ post-injection, and that the frequency of these emboli was increased in mice pre-treated with high doses of sunitinib. Interestingly, we found that 4T1 tumour cell emboli were trapped preferentially in areas of the lung with low pericyte coverage. Since we also show that high doses of sunitinib lead to reduced pericyte coverage in the lung vasculature, it is possible that sunitinib enhances 4T1 lung metastasis due to the propensity for 4T1 emboli to preferentially seed in vessels with low pericyte coverage. It should be noted that pre-treatment of mice with lower sunitinib doses did not reduce pericyte coverage in the lung. We conclude from this that the pericyte depletion effect noted with $120 \mathrm{mg} / \mathrm{kg} /$ day sunitinib is likely an offtarget effect of the drug. Of interest, previous studies have demonstrated that pericytes in the primary tumour can limit metastasis [13, 64]. However, we believe this is the first demonstration that pericytes may also limit the seeding of cells at the site of metastasis. Importantly, pericytes can signal in a paracrine fashion to endothelial cells, and may also control capillary constriction, which could both potentially be involved in regulating the metastatic niche [4].

We also examined the effects of sunitinib when it was administered to mice after the intravenous inoculation of tumour cells. While sunitinib failed to suppress the growth of 4T1 lung metastases in this scenario, the same drug suppressed the growth of RENCA lung metastases. Investigating the underlying mechanisms for this differential response, we found that whilst the vascularisation of RENCA tumours was potently inhibited by sunitinib, 4T1 tumour nodules continued to grow with a well-vascularised viable tumour rim. Functional imaging performed in mRCC patients demonstrates that sunitinib refractory lesions often show signs of extensive central devascularisation, but that the rim of these tumours continues to be well vascularised [56, 57]. Therefore, continued vascularisation in this viable tumour rim may be a distinguishing feature of some lesions that are refractory to angiogenesis inhibition. The vascularisation mechanisms in this viable rim deserve further study, as they may present a target for therapeutic intervention. Notably, we observed that 4T1 
Fig. 8 Quantification of pericyte coverage and myeloid cell recruitment in tumours. $\mathrm{Balb} / \mathrm{c}$ mice were injected intravenously with 4T1-luc or RENCA-luc cells and then treated with vehicle (veh) or $60 \mathrm{mg} / \mathrm{kg} /$ day sunitinib (sun) for 14 days, at which time point mice were culled and lungs were collected for histological analysis. a, b Quantification of pericyte coverage in 4T1 and RENCA tumours treated with vehicle or sunitinib. Bar graph in a shows percentage colocalisation between CD31 and NG2 \pm SEM.

$* P=0.0001, \mathrm{n}=8$ mice per treatment group. In $\mathbf{b}$, representative high power fields from each experimental group are shown with CD31 (red), NG2 (green) and DAPI (blue). c Representative high power field containing Gr1 and CD11b dual positive cells (arrowheads). Staining for Gr1 (green), CD11b+ (red) and

DAPI (blue). d, e Quantification of Gr1 and CD11b dual positive cells in 4T1 and RENCA tumour nodules from vehicle and sunitinib treated mice. Graph in d shows number of Gr1/CD11b + cells per $\mathrm{mm}^{2} \pm$ SEM. $* P=0.02$, $* * P=0.007, \mathrm{n}=8$ mice per treatment group. In $\mathbf{e}$,

representative low power fields from each experimental group are shown with CD31 (red), Gr1 (green) and DAPI (blue).

CD11b staining is omitted in e, but all of the cells shown were confirmed to be dual positive for both Gr1 and CD11b. Scale bar $=20 \mu \mathrm{M}$ in $\mathbf{b}$ and $\mathbf{c}$ and $50 \mu \mathrm{M}$ in e. (Color figure online)
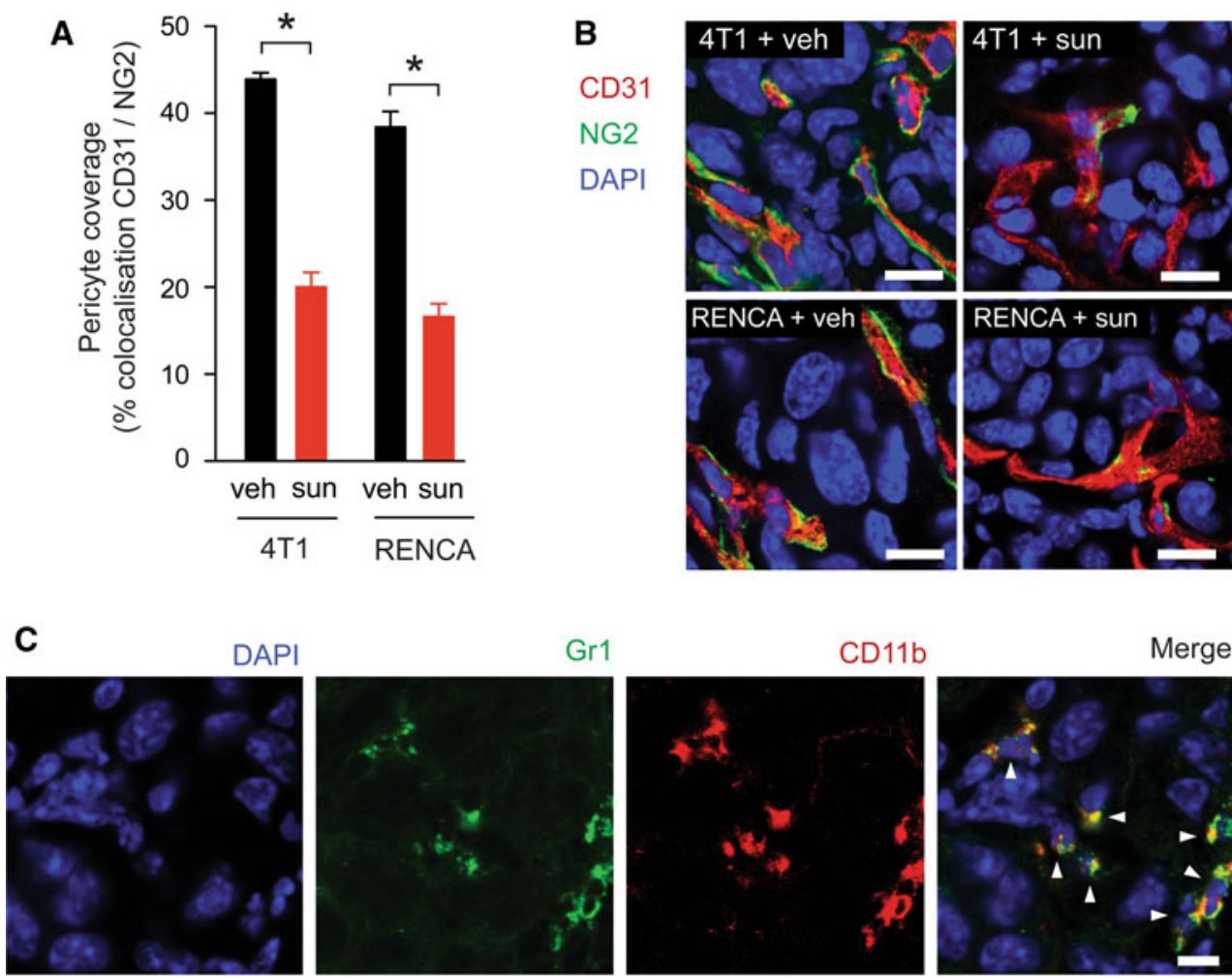

Gr1

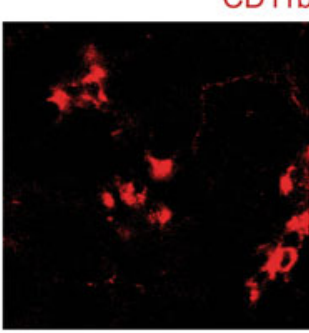

CD11b
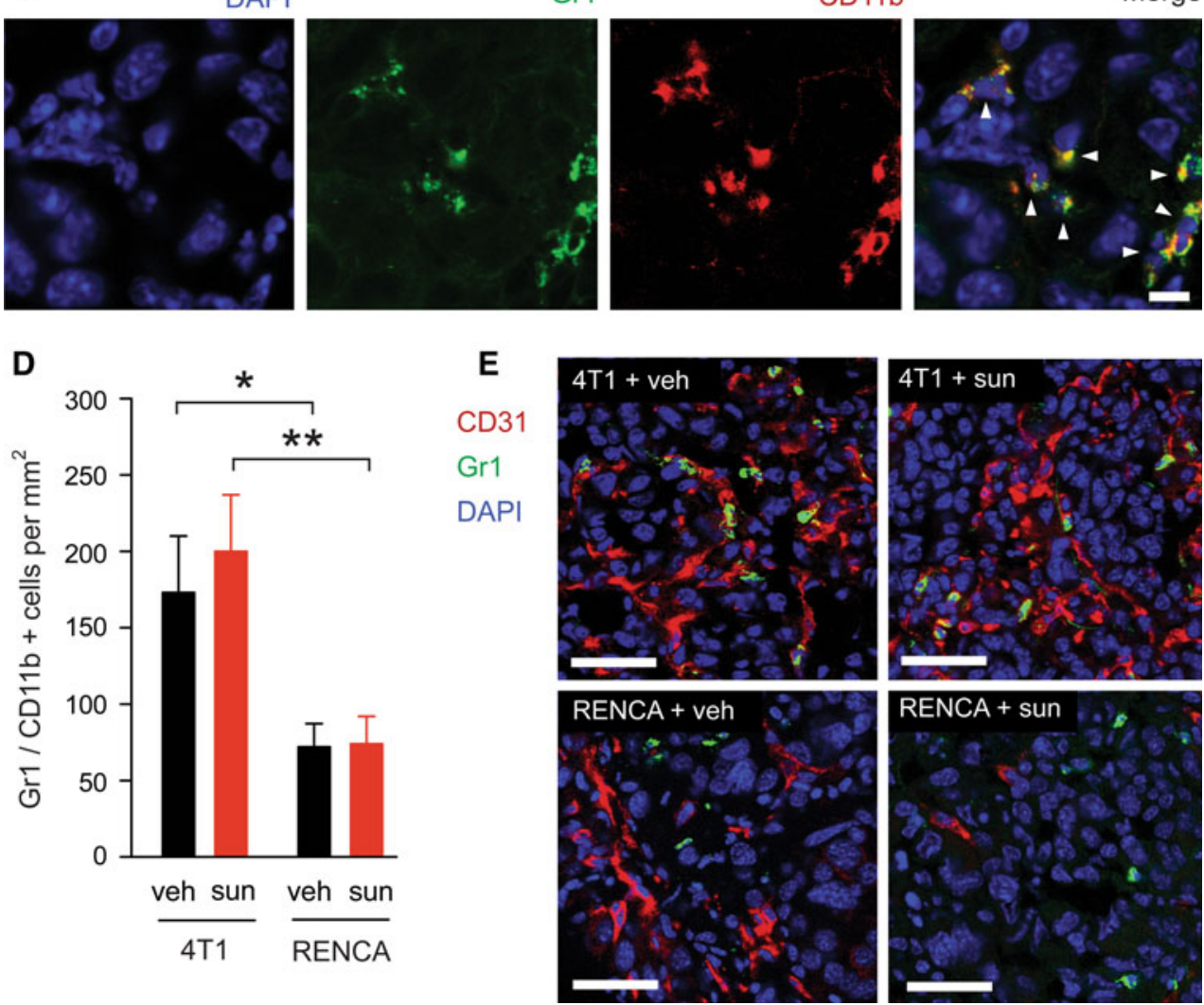

tumours recruited more pro-angiogenic Gr1+CD11b+ myeloid cells than RENCA tumours and that these cells were associated with the vasculature in 4T1 tumours, but not in RENCA tumours. These myeloid cells mediate resistance to angiogenesis inhibitors in several pre-clinical models, including subcutaneously implanted 4T1 tumours [26, 37, 49, 54]. The recruitment of these cells may therefore contribute to the ability of 4T1 tumours to remain vascularised and progress, despite sunitinib treatment. Other possible explanations for persistent growth of tumours despite sunitinib treatment are: the presence of alternative soluble pro-angiogenic factors [34, 61], alternative modes of tumour vascularisation [16, 38] or a hypoxia-driven increase in the stem cell component of tumours [12].

We demonstrated that sunitinib fails to prolong overall survival in the 4T1 model when it was administered after intravenous tumour cell injection, indeed we even observed shortening of overall survival in this scenario. This is in agreement with a previous report, which showed that sunitinib administered after intravenous injection of MDAMB-231 cells can shorten overall survival in mice [18]. 
Fig. 9 Measurement of tumour glucose uptake. Balb/c mice were injected intravenously with 4T1-luc cells $(\mathbf{a}-\mathbf{c})$ or RENCA-luc cells $(\mathbf{d}-\mathbf{f})$ and then treated with daily vehicle or $60 \mathrm{mg} / \mathrm{kg} /$ day sunitinib on a continuous dosing schedule. ${ }^{18}$ FDG uptake was measured by ${ }^{18}$ FDG-PET/CT imaging of live animals or by gamma counting of resected tissues. a, d Graphs show mean standard uptake value (SUV) measured in the lungs of 4T1 (a) or RENCA (d) tumour-bearing mice using ${ }^{18}$ FDG-PET/CT imaging at the indicated time point. $* P=0.02$, $* * P=0.002, \mathrm{n}=2$ mice per experimental group (left and right lungs from each mouse were analysed separately). b, e Representative ${ }^{18}$ FDG-PET/ CT images are shown of 4T1 tumour bearing mice at 14 days (b) and RENCA tumour bearing mice at 19 days (e) after tumour cell implantation, respectively. Arrowhead indicates location of chest cavity. c, f Gamma counting was used to measure the amount of ${ }^{18}$ FDG present in lungs, blood and muscle obtained post-mortem from 4T1 (c) or RENCA (f) tumour bearing mice at 14 days (c) or 19 days (f) after tumour cell implantation, respectively. Counts were corrected to the tissue mass in order to calculate the percentage injected dose present per gram of tissue. The graphs show the percentage injected dose per gram of tissue \pm SEM. $* P=0.01$, $\mathrm{n}=7-10$ mice per experimental group. NS $=$ no significant difference
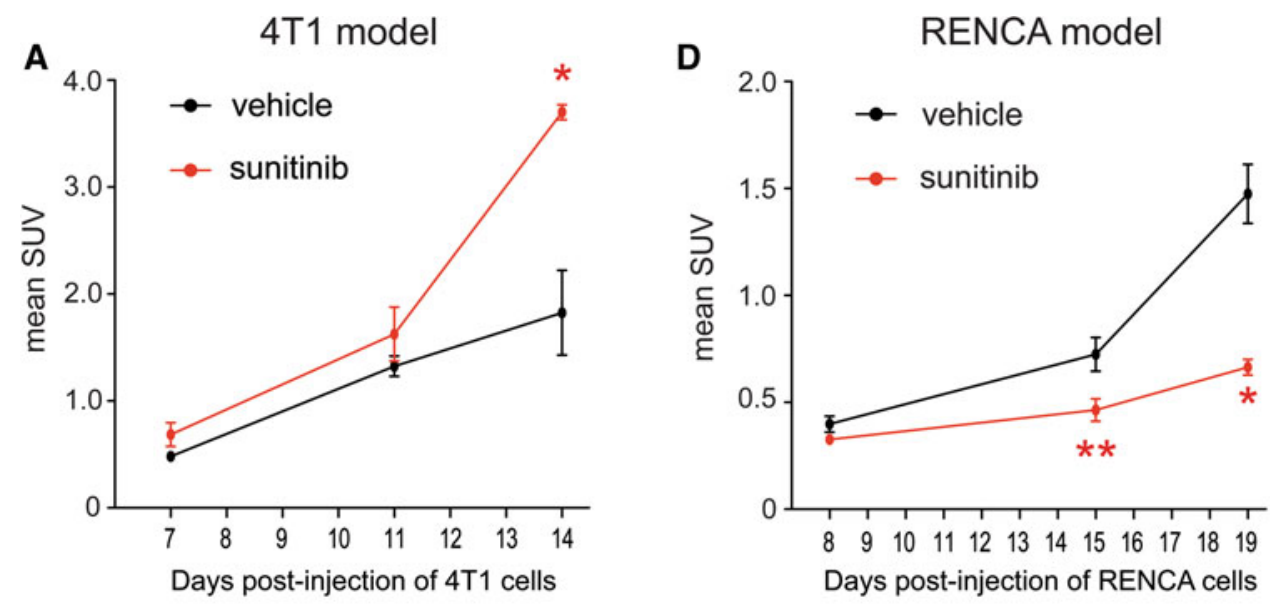

B
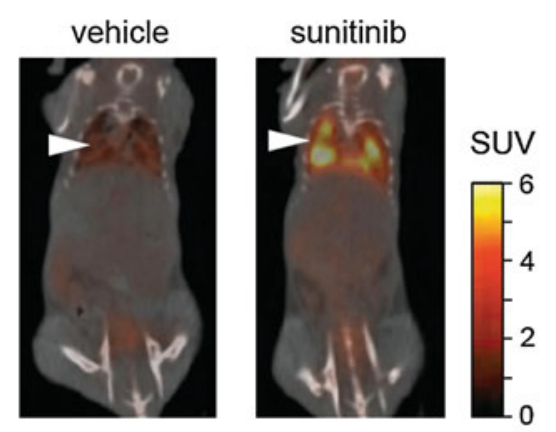

E
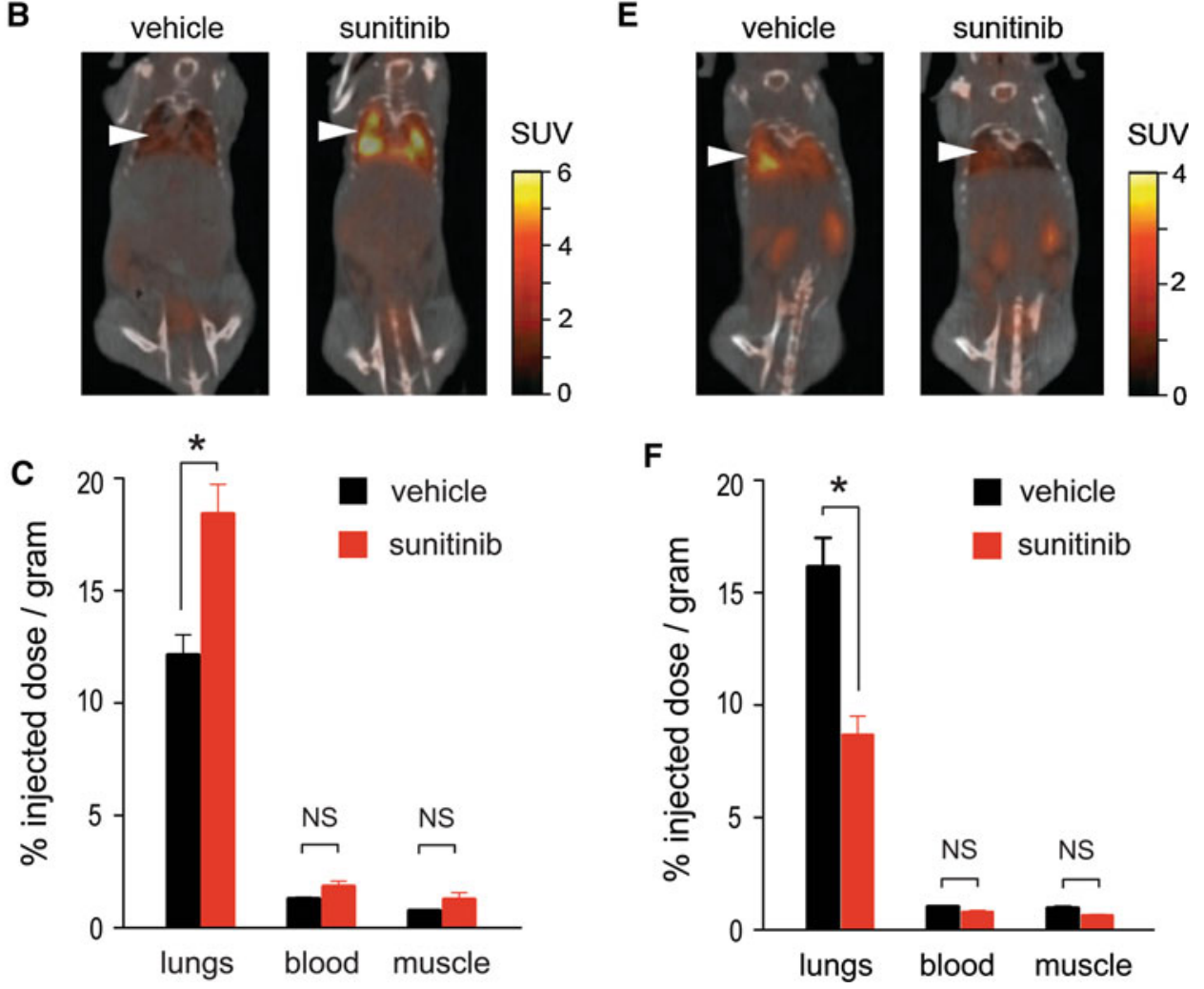

F

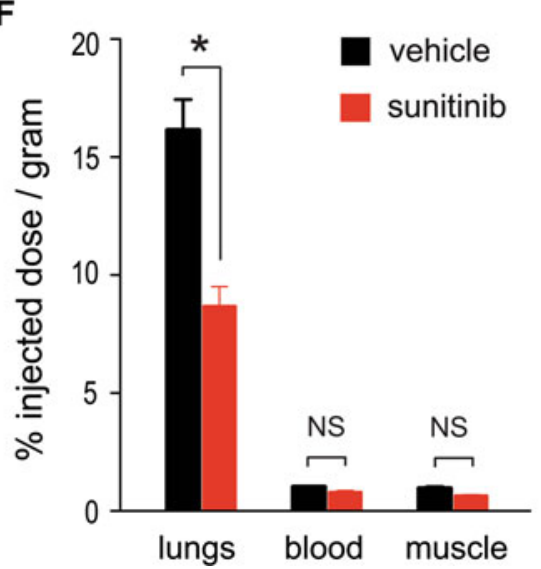

However, in contrast to Ebos et al., we did not find evidence for enhanced tumour growth in mice administered sunitinib after intravenous tumour cell injection, either in the lungs or in other organs (Fig. 5 and data not shown), suggesting that enhanced tumour growth may not account for the premature mortality observed in our study. Interestingly, we observed rapid weight loss in 4T1 tumourbearing mice treated with sunitinib in comparison to the other experimental groups (see Table 2) suggesting that cancer-associated weight loss (cachexia) in this cohort may be accelerated. The mechanisms driving cachexia in tumour bearing individuals are poorly understood. However, it has been proposed that a major cause of cachexia is the aggressive metabolism of glucose and glutamine by tumours, because this can place an enormous metabolic stress on the body [15, 58]. Importantly, we observed increased tumour glucose metabolism in the lungs of 4T1 tumour bearing mice after 14 days of sunitinib treatment, which coincided with the manifestation of weight loss in these mice. We speculate that this enhanced tumour glucose consumption places a significant metabolic burden on these mice, which could accelerate cachexia. However, we cannot rule out the possibility that other mechanisms, including drug toxicity, may underlie the premature death of 4T1 tumour bearing mice treated with sunitinib. Of interest, we recently examined FDG-PET/CT as a 
Table 2 Time taken for $10 \%$ weight loss to occur in each experimental group

\begin{tabular}{lll}
\hline \multirow{2}{*}{ Cohort } & \multicolumn{2}{l}{ Treatment received } \\
\cline { 2 - 3 } & Vehicle & $60 \mathrm{mg} / \mathrm{kg} /$ day sunitinib \\
\hline $4 \mathrm{~T} 1$ & $20.25 \pm 0.86$ days & $16.25 \pm 0.66$ days** \\
RENCA & $23.25 \pm 0.29$ days & $35.25 \pm 0.60$ days \\
Tumour free & No weight loss observed & $37.00 \pm 0.82$ days \\
\hline
\end{tabular}

Mice were inoculated intravenously with 4T1-luc or RENCA-luc tumour cells, or left tumour free, and were then treated continuously with daily vehicle or daily $60 \mathrm{mg} / \mathrm{kg} /$ day sunitinib and weight loss was recorded. The time taken for $10 \%$ weight loss to occur in each experimental group \pm SEM is shown. $\mathrm{n}=8$ mice per experimental group

$* * P=0.004$ when compared to $4 \mathrm{~T} 1$ tumour bearing mice treated with vehicle

predictive biomarker of response to sunitinib in mRCC. Patients with highly metabolically active disease at baseline responded poorly to treatment with sunitinib in terms of overall survival benefit, in comparison to sunitinib treated patients with less metabolically active disease who survived significantly longer on treatment [36]. Taken together, the pre-clinical and clinical data suggest that a high rate of tumour metabolism may be associated with a lack of response to angiogenesis inhibitors. Moreover, targeting pathways involved in metabolic adaptation to anti-angiogenic therapy might be a potential therapeutic strategy to improve the clinical efficacy of angiogenesis inhibition [40].

The experimental models used here have their limitations. In particular, our study was limited to the use of only two murine tumour cell lines and only one angiogenesis inhibitor, so extrapolation to human subjects and other drugs that target the VEGF pathway should be approached with due caution. In addition, our study did not address the ability of sunitinib to promote metastasis from the primary tumour, so no inference can be made regarding the effects of sunitinib on the formation of distant metastasis when it is used in the neoadjuvant setting. Interestingly, recent work suggests that although tyrosine kinase inhibitors can promote metastasis in some mouse models, anti-VEGF monoclonal antibodies do not $[13,55]$. In spite of these limitations, our study does have important implications. We did not observe a conditioning effect that promotes the growth of metastases when sunitinib was used at clinically relevant doses, suggesting that a conditioning effect is unlikely to accelerate the growth of metastases in patients. This is important, given that large adjuvant studies of VEGF-targeted agents, such as sunitinib, are currently underway and because patients with metastatic disease also continue to be treated with these agents. Instead, we replicate in mice the responses that are seen clinically with VEGF receptor targeted agents: lack of tumour response to therapy is associated with a poor outcome, whereas suppression of tumour growth is associated with an extension in overall survival [30]. We propose that a mixture of both tumour autonomous mechanisms and elements within the microenvironment conspire to determine the response to anti-angiogenic therapy within individual tumours. In light of these findings, research should now be focused on understanding the aspects of tumour cell biology that determine response and resistance to anti-angiogenic therapies.

Acknowledgments We thank the biological services unit staff and the Breakthrough Breast Cancer histopathology facility staff for technical assistance. We thank Naveen Vasudev and Clare Isacke for critical comments on the manuscript. The study was funded by Breakthrough Breast Cancer. We also acknowledge support from the Royal Marsden NIHR Biomedical Research Centre.

Conflict of interest The authors declare that they have no conflict of interest.

Open Access This article is distributed under the terms of the Creative Commons Attribution License which permits any use, distribution, and reproduction in any medium, provided the original author(s) and the source are credited.

\section{References}

1. Abrams TJ, Lee LB, Murray LJ, Pryer NK, Cherrington JM (2003) SU11248 inhibits KIT and platelet-derived growth factor receptor beta in preclinical models of human small cell lung cancer. Mol Cancer Ther 2:471-478

2. Abrams TJ, Murray LJ, Pesenti E, Holway VW, Colombo T, Lee LB et al (2003) Preclinical evaluation of the tyrosine kinase inhibitor SU11248 as a single agent and in combination with "standard of care" therapeutic agents for the treatment of breast cancer. Mol Cancer Ther 2:1011-1021

3. Airley RE, Loncaster J, Raleigh JA, Harris AL, Davidson SE, Hunter RD et al (2003) GLUT-1 and CAIX as intrinsic markers of hypoxia in carcinoma of the cervix: relationship to pimonidazole binding. Int J Cancer 104:85-91

4. Armulik A, Genove G, Betsholtz C (2011) Pericytes: developmental, physiological, and pathological perspectives, problems, and promises. Dev Cell 21:193-215

5. Azam F, Mehta S, Harris AL (2010) Mechanisms of resistance to antiangiogenesis therapy. Eur J Cancer 46:1323-1332

6. Batchelor TT, Sorensen AG, di Tomaso E, Zhang WT, Duda DG, Cohen KS et al (2007) AZD2171, a pan-VEGF receptor tyrosine kinase inhibitor, normalizes tumor vasculature and alleviates edema in glioblastoma patients. Cancer Cell 11:83-95

7. Bergers G, Hanahan D (2008) Modes of resistance to antiangiogenic therapy. Nat Rev Cancer 8:592-603

8. Brahimi-Horn MC, Chiche J, Pouyssegur J (2007) Hypoxia and cancer. J Mol Med (Berlin) 85:1301-1307

9. Britten CD, Kabbinavar F, Hecht JR, Bello CL, Li J, Baum C et al (2008) A phase I and pharmacokinetic study of sunitinib administered daily for 2 weeks, followed by a 1-week off period. Cancer Chemother Pharmacol 61:515-524

10. Burstein HJ, Elias AD, Rugo HS, Cobleigh MA, Wolff AC, Eisenberg PD et al (2008) Phase II study of sunitinib malate, an oral 
multitargeted tyrosine kinase inhibitor, in patients with metastatic breast cancer previously treated with an anthracycline and a taxane. J Clin Oncol 26:1810-1816

11. Chung AS, Kowanetz M, Wu X, Zhuang G, Ngu H, Finkle D et al (2012) Differential drug-class specific metastatic effects following treatment with a panel of angiogenesis inhibitors. J Pathol. doi:10.1002/path.4052

12. Conley SJ, Gheordunescu E, Kakarala P, Newman B, Korkaya H, Heath AN et al (2012) Antiangiogenic agents increase breast cancer stem cells via the generation of tumor hypoxia. Proc Natl Acad Sci USA 109:2784-2789

13. Cooke VG, Lebleu VS, Keskin D, Khan Z, O'Connell JT, Teng Y et al (2012) Pericyte depletion results in hypoxia-associated epithelial-to-mesenchymal transition and metastasis mediated by met signaling pathway. Cancer Cell 21:66-81

14. Dang DT, Chun SY, Burkitt K, Abe M, Chen S, Havre P et al (2008) Hypoxia-inducible factor-1 target genes as indicators of tumor vessel response to vascular endothelial growth factor inhibition. Cancer Res 68:1872-1880

15. DeBerardinis RJ, Cheng T (2010) Q's next: the diverse functions of glutamine in metabolism, cell biology and cancer. Oncogene 29:313-324

16. Dome B, Hendrix MJ, Paku S, Tovari J, Timar J (2007) Alternative vascularization mechanisms in cancer: pathology and therapeutic implications. Am J Pathol 170:1-15

17. Ebos JM, Lee CR, Christensen JG, Mutsaers AJ, Kerbel RS (2007) Multiple circulating proangiogenic factors induced by sunitinib malate are tumor-independent and correlate with antitumor efficacy. Proc Natl Acad Sci USA 104:17069-17074

18. Ebos JM, Lee CR, Cruz-Munoz W, Bjarnason GA, Christensen JG, Kerbel RS (2009) Accelerated metastasis after short-term treatment with a potent inhibitor of tumor angiogenesis. Cancer Cell 15:232-239

19. Ebos JM, Lee CR, Kerbel RS (2009) Tumor and host-mediated pathways of resistance and disease progression in response to antiangiogenic therapy. Clin Cancer Res 15:5020-5025

20. Ellis LM, Hicklin DJ (2008) VEGF-targeted therapy: mechanisms of anti-tumour activity. Nat Rev Cancer 8:579-591

21. Ellis LM, Reardon DA (2009) Cancer: the nuances of therapy. Nature 458:290-292

22. Ellis LM, Reardon DA (2010) Is there really a yin and yang to VEGF-targeted therapies? Lancet Oncol 11:809-811

23. Eskens FA, Sleijfer S (2008) The use of bevacizumab in colorectal, lung, breast, renal and ovarian cancer: where does it fit? Eur J Cancer 44:2350-2356

24. Faivre S, Delbaldo C, Vera K, Robert C, Lozahic S, Lassau N et al (2006) Safety, pharmacokinetic, and antitumor activity of SU11248, a novel oral multitarget tyrosine kinase inhibitor, in patients with cancer. J Clin Oncol 24:25-35

25. Faivre S, Demetri G, Sargent W, Raymond E (2007) Molecular basis for sunitinib efficacy and future clinical development. Nat Rev Drug Discov 6:734-745

26. Finke J, Ko J, Rini B, Rayman P, Ireland J, Cohen P (2011) MDSC as a mechanism of tumor escape from sunitinib mediated anti-angiogenic therapy. Int Immunopharmacol 11:856-861

27. Franco M, Man S, Chen L, Emmenegger U, Shaked Y, Cheung AM et al (2006) Targeted anti-vascular endothelial growth factor receptor-2 therapy leads to short-term and long-term impairment of vascular function and increase in tumor hypoxia. Cancer Res 66:3639-3648

28. Gerber HP, Ferrara N (2005) Pharmacology and pharmacodynamics of bevacizumab as monotherapy or in combination with cytotoxic therapy in preclinical studies. Cancer Res 65:671-680

29. Gotink KJ, Verheul HM (2010) Anti-angiogenic tyrosine kinase inhibitors: what is their mechanism of action? Angiogenesis $13: 1-14$
30. Heng DY, Mackenzie MJ, Vaishampayan UN, Bjarnason GA, Knox JJ, Tan MH et al (2012) Primary anti-vascular endothelial growth factor (VEGF)-refractory metastatic renal cell carcinoma: clinical characteristics, risk factors, and subsequent therapy. Ann Oncol 23:1549-1555

31. Houk BE, Bello CL, Poland B, Rosen LS, Demetri GD, Motzer RJ (2010) Relationship between exposure to sunitinib and efficacy and tolerability endpoints in patients with cancer: results of a pharmacokinetic/pharmacodynamic meta-analysis. Cancer Chemother Pharmacol 66:357-371

32. Huang J, Frischer JS, Serur A, Kadenhe A, Yokoi A, McCrudden KW et al (2003) Regression of established tumors and metastases by potent vascular endothelial growth factor blockade. Proc Natl Acad Sci USA 100:7785-7790

33. Huang D, Ding Y, Li Y, Luo WM, Zhang ZF, Snider J et al (2010) Sunitinib acts primarily on tumor endothelium rather than tumor cells to inhibit the growth of renal cell carcinoma. Cancer Res 70:1053-1062

34. Huang D, Ding Y, Zhou M, Rini BI, Petillo D, Qian CN et al (2010) Interleukin-8 mediates resistance to antiangiogenic agent sunitinib in renal cell carcinoma. Cancer Res 70:1063-1071

35. Hurwitz H, Fehrenbacher L, Novotny W, Cartwright T, Hainsworth J, Heim W et al (2004) Bevacizumab plus irinotecan, fluorouracil, and leucovorin for metastatic colorectal cancer. N Engl J Med 350:2335-2342

36. Kayani I, Avril N, Bomanji J, Chowdhury S, Rockall A, Sahdev A et al (2011) Sequential FDG-PET/CT as a biomarker of response to Sunitinib in metastatic clear cell renal cancer. Clin Cancer Res 17:6021-6028

37. Ko JS, Rayman P, Ireland J, Swaidani S, Li G, Bunting KD et al (2010) Direct and differential suppression of myeloid-derived suppressor cell subsets by sunitinib is compartmentally constrained. Cancer Res 70:3526-3536

38. Leite de Oliveira R, Hamm A, Mazzone M (2011) Growing tumor vessels: more than one way to skin a cat-implications for angiogenesis targeted cancer therapies. Mol Aspects Med 32:71-87

39. Loges S, Mazzone M, Hohensinner P, Carmeliet P (2009) Silencing or fueling metastasis with VEGF inhibitors: antiangiogenesis revisited. Cancer Cell 15:167-170

40. McIntyre A, Patiar S, Wigfield S, Li JL, Ledaki I, Turley H et al (2012) Carbonic anhydrase IX promotes tumor growth and necrosis in vivo and inhibition enhances anti-VEGF therapy. Clin Cancer Res 18:3100-3111

41. Mendel DB, Laird AD, Xin X, Louie SG, Christensen JG, Li G et al (2003) In vivo antitumor activity of SU11248, a novel tyrosine kinase inhibitor targeting vascular endothelial growth factor and platelet-derived growth factor receptors: determination of a pharmacokinetic/pharmacodynamic relationship. Clin Cancer Res 9:327-337

42. Miles D, Harbeck N, Escudier B, Hurwitz H, Saltz L, Van Cutsem E et al (2011) Disease course patterns after discontinuation of bevacizumab: pooled analysis of randomized phase III trials. J Clin Oncol 29:83-88

43. Miller K, Wang M, Gralow J, Dickler M, Cobleigh M, Perez EA et al (2007) Paclitaxel plus bevacizumab versus paclitaxel alone for metastatic breast cancer. N Engl J Med 357:2666-2676

44. Motzer RJ, Hutson TE, Tomczak P, Michaelson MD, Bukowski $\mathrm{RM}$, Rixe $\mathrm{O}$ et al (2007) Sunitinib versus interferon alfa in metastatic renal-cell carcinoma. N Engl J Med 356:115-124

45. Motzer RJ, Hutson TE, Tomczak P, Michaelson MD, Bukowski RM, Oudard S et al (2009) Overall survival and updated results for sunitinib compared with interferon alfa in patients with metastatic renal cell carcinoma. J Clin Oncol 27:3584-3590

46. O'Farrell AM, Abrams TJ, Yuen HA, Ngai TJ, Louie SG, Yee $\mathrm{KW}$ et al (2003) SU11248 is a novel FLT3 tyrosine kinase 
inhibitor with potent activity in vitro and in vivo. Blood 101:3597-3605

47. Paez-Ribes M, Allen E, Hudock J, Takeda T, Okuyama H, Vinals F et al (2009) Antiangiogenic therapy elicits malignant progression of tumors to increased local invasion and distant metastasis. Cancer Cell 15:220-231

48. Prewett M, Huber J, Li Y, Santiago A, O'Connor W, King K et al (1999) Antivascular endothelial growth factor receptor (fetal liver kinase 1) monoclonal antibody inhibits tumor angiogenesis and growth of several mouse and human tumors. Cancer Res 59:5209-5218

49. Priceman SJ, Sung JL, Shaposhnik Z, Burton JB, Torres-Collado AX, Moughon DL et al (2010) Targeting distinct tumor-infiltrating myeloid cells by inhibiting CSF-1 receptor: combating tumor evasion of antiangiogenic therapy. Blood 115:1461-1471

50. Rini BI, Atkins MB (2009) Resistance to targeted therapy in renal-cell carcinoma. Lancet Oncol 10:992-1000

51. Sandler A, Gray R, Perry MC, Brahmer J, Schiller JH, Dowlati A et al (2006) Paclitaxel-carboplatin alone or with bevacizumab for non-small-cell lung cancer. N Engl J Med 355:2542-2550

52. Sennino B, Ishiguro-Oonuma T, Wei Y, Naylor RM, Williamson CW, Bhagwandin V et al (2012) Suppression of tumor invasion and metastasis by concurrent inhibition of c-Met and VEGF signaling in pancreatic neuroendocrine tumors. Cancer Discov 2:270-287

53. Shojaei F, Ferrara N (2008) Refractoriness to antivascular endothelial growth factor treatment: role of myeloid cells. Cancer Res 68:5501-5504

54. Shojaei F, Wu X, Malik AK, Zhong C, Baldwin ME, Schanz S et al (2007) Tumor refractoriness to anti-VEGF treatment is mediated by $\mathrm{CD} 11 \mathrm{~b}+\mathrm{Gr} 1+$ myeloid cells. Nat Biotechnol 25:911-920

55. Singh M, Couto SS, Forrest WF, Lima A, Cheng JH, Molina R et al (2012) Anti-VEGF antibody therapy does not promote metastasis in genetically engineered mouse tumor models. J Pathol. doi:10.1002/path.4053
56. Smith AD, Lieber ML, Shah SN (2010) Assessing tumor response and detecting recurrence in metastatic renal cell carcinoma on targeted therapy: importance of size and attenuation on contrastenhanced CT. AJR Am J Roentgenol 194:157-165

57. Smith AD, Shah SN, Rini BI, Lieber ML, Remer EM (2010) Morphology, Attenuation, Size, and Structure (MASS) criteria: assessing response and predicting clinical outcome in metastatic renal cell carcinoma on antiangiogenic targeted therapy. AJR Am J Roentgenol 194:1470-1478

58. Tisdale MJ (2009) Mechanisms of cancer cachexia. Physiol Rev 89:381-410

59. Torres Filho IP, Leunig M, Yuan F, Intaglietta M, Jain RK (1994) Noninvasive measurement of microvascular and interstitial oxygen profiles in a human tumor in SCID mice. Proc Natl Acad Sci USA 91:2081-2085

60. Verheul HM, Hammers H, van Erp K, Wei Y, Sanni T, Salumbides B et al (2007) Vascular endothelial growth factor trap blocks tumor growth, metastasis formation, and vascular leakage in an orthotopic murine renal cell cancer model. Clin Cancer Res 13:4201-4208

61. Welti JC, Gourlaouen M, Powles T, Kudahetti SC, Wilson P, Berney DM et al (2011) Fibroblast growth factor 2 regulates endothelial cell sensitivity to sunitinib. Oncogene 30:1183-1193

62. Wong CW, Lee A, Shientag L, Yu J, Dong Y, Kao G et al (2001) Apoptosis: an early event in metastatic inefficiency. Cancer Res 61:333-338

63. Wong CW, Song C, Grimes MM, Fu W, Dewhirst MW, Muschel $\mathrm{RJ}$ et al (2002) Intravascular location of breast cancer cells after spontaneous metastasis to the lung. Am J Pathol 161:749-753

64. Xian X, Hakansson J, Stahlberg A, Lindblom P, Betsholtz C, Gerhardt $\mathrm{H}$ et al (2006) Pericytes limit tumor cell metastasis. J Clin Invest 116:642-651

65. Yang L, DeBusk LM, Fukuda K, Fingleton B, Green-Jarvis B, Shyr Y et al (2004) Expansion of myeloid immune suppressor $\mathrm{Gr}+\mathrm{CD} 11 \mathrm{~b}+$ cells in tumor-bearing host directly promotes tumor angiogenesis. Cancer Cell 6:409-421 